\title{
EL CÓDIGO DE PROTECCIÓN Y DEFENSA DEL CONSUMIDOR VISTO A TRAVÉS DE LA JURISPRUDENCIA DEL INDECOPI: CONSOLIDACIÓN NECESARIA DE SUS CRITERIOS INTERPRETATIVOS
}

\author{
CÉSAR CARRANZA ÁLVAREZ ${ }^{1}$
}

\section{Resumen}

En el presente escrito, el autor efectúa un recuento de los criterios interpretativos planteados por la Sala Especializada en Protección al Consumidor del Instituto Nacional de Defensa de la Competencia y de la Protección de la Propiedad Intelectual, del Perú, a partir de casos puntuales resueltos por ella; en temas relacionados a la noción de consumidor, protección de los terceros expuestos a una relación de consumo, usos mixtos, derecho de información, deber de idoneidad y discriminación. Dichos criterios son analizados a la luz de la normativa del Código de Protección y Defensa del Consumidor y la doctrina nacional que ha opinado sobre ellos.

Palabras clave: consumidor, proveedor, relación de consumo, mercado, jurisprudencia Indecopi.

\section{1) Nota del autor}

Al cumplirse cuatro años de la vigencia del Código de Protección y Defensa del Consumidor peruano [CPDC], resulta imprescindible efectuar una consolidación de los principales criterios interpretativos establecidos por la Sala Especializada en Protección al Consumidor del Instituto Nacional de Defensa de la Competencia y de la Protección de la

\footnotetext{
1 Abogado, profesor universitario y árbitro. Magíster en Derecho de la Empresa por la Pontificia Universidad Católica del Perú y Doctorado en Derecho y Ciencias Políticas en la Universidad Nacional de Trujillo. Cuenta con estudios de especialización en Arbitraje, Derecho de Contratos y Protección del Consumidor. Ha realizado estancia docente y de investigación en la Facultad de Derecho de la Universidad de Medellín (Colombia). Socio Fundador de SABA.ED Escuela de Derecho (Lima). Miembro del Comité Consultivo de ATHINA, revista editada por estudiantes de la Facultad de Derecho de la Universidad de Lima.
} 


\section{Revista Eletrônica da Faculdade de Direito da Universidade Federal de Pelotas (UFPel) Dossiê Consumo e Vulnerabilidade: a proteção jurídica dos consumidores no século XXI. Vol. 03, N. 1, Jan-Jun., 2017.}

ISSN - 2448-3303

Propiedad Intelectual [en adelante, INDECOPI], en los casos vinculados a la calificación legal de consumidor, la situación de los microempresarios, la tutela de los denominados consumidores periféricos, el uso mixto de bienes y servicios, el derecho de información, el deber de idoneidad y discriminación. No niego que existan otros temas de interés, sin embargo, los indicados son los que han generado mayor controversia en la doctrina nacional y sobre los cuales me he pronunciado en su oportunidad, por lo que es necesario volver tras estos pasos para reafirmar o modificar lo dicho, así como evaluar las críticas efectuadas.

Conforme a la Nota del Autor, el presente texto fue terminando, en su versión original, cuando el CPDC contaba con 4 años de vigencia. Al acercarse ya a los 7 años, mucha agua ha corrido bajo el puente, por lo que es necesario dar cuenta, en esta versión actualizada, de las señas más importantes de este periodo reciente.

La defensa de los derechos del consumidor en el Perú se realiza en dos vías distintas: una, de naturaleza administrativa; la otra, de naturaleza civil [sin perjuicio de la penal, cuando el caso lo amerite]. En la primera, tiene competencia el INDECOPI, quien de acuerdo al artículo 105 del $\mathrm{CPDC}^{2}$ constituye la autoridad con competencia primaria y de alcance nacional para conocer las presuntas infracciones a las disposiciones del Código, así como para imponer las sanciones y medidas correctivas que correspondan. Tal se viabiliza por medio de sendos procedimientos administrativos, uno de los cuales, el sumarísimo, está orientado a resolver con celeridad los conflictos suscitados entre los consumidores y proveedores, siempre y cuando la cuantía de los productos y servicios objeto del mismo no sobrepase las 3 Unidades Impositivas Tributarias; ${ }^{3}$ así como para conocer denuncias que versen sobre la falta de atención a reclamos y requerimientos de información, métodos abusivos de cobranza, falta de entrega del producto, con independencia de su cuantía. Del mismo modo, denuncias sobre incumplimiento de medida correctiva, acuerdos conciliatorios y liquidación de costas y costos. El Órgano Resolutivo de Procedimientos Sumarísimos (ORPS), que actúa como primera instancia administrativa, no puede conocer denuncias relativas a reclamos por sustancias o productos peligrosos, discriminación o trato diferenciado, servicios médicos, actos que afecten intereses colectivos o difusos o los que se refieran a productos o servicios que superen la cuantía atrás indicada. Las resoluciones emitidas

\footnotetext{
2 Esta norma fue modificada por el Decreto Legislativo $\mathrm{N}^{\circ} 1308$, publicado en el diario oficial El Peruano el 30.12.2016. El texto citado no ha sufrido variación alguna.

${ }^{3}$ La Unidad Impositiva Tributaria [UIT] para el periodo 2014 fue 3800 nuevos soles. Para el año 2017, se la ha fijado en 4050 nuevos soles, según el D.S. N 353-2016-EF, publicado en el diario oficial El Peruano el 22.12.2016. Los montos antes indicados se modifican cada año.
} 


\title{
Revista Eletrônica da Faculdade de Direito da Universidade Federal de Pelotas (UFPel) Dossiê Consumo e Vulnerabilidade: a proteção jurídica dos consumidores no século XXI. Vol. 03, N. 1, Jan-Jun., 2017.
}

ISSN - 2448-3303

por este órgano son impugnadas ante la Comisión de Protección al Consumidor o la comisión con facultades desconcentradas, que constituye la segunda instancia administrativa en este procedimiento, cuyas resoluciones agotan la vía, pudiendo ser cuestionadas luego en el Poder Judicial por medio del proceso contencioso-administrativo. ${ }^{4}$

En dicho procedimiento, antes de la expedición del Decreto Legislativo $\mathrm{N}^{\circ} 1308$ que modificó diversos artículos del CPDC [véase nota a pie 1], las resoluciones de la Comisión podían ser elevadas, mediante Recurso de Revisión, a la Sala Especializada en Protección al Consumidor, que solo analizaba cuestiones de puro derecho. Esto se ha suprimido ahora, pero manteniéndose la competencia de la Sala para resolver recursos de apelación derivados de los restantes procedimientos tramitados ante la autoridad administrativa. Hago esta observación porque en las líneas que siguen aparece reiteradamente la mención a dicho medio impugnatorio, por lo que cuando esto ocurra tendrá que recordarse lo anotado precedentemente.

\begin{abstract}
Estando en la fase de revisión de estas líneas, aparecen publicadas dos directivas orientadas a normar los procedimientos administrativos en materia de defensa del consumidor. La primera es la Directiva $N^{\circ}$ 005-2017/DIR-COD-INDECOPI, publicada en el diario oficial El Peruano el 28.4.2017, que regula el procedimiento sumarísimo; y la segunda, la Directiva $N^{\circ}$ 006-2017/DIR-COD-INDECOPI, publicada en el diario oficial $E l$ Peruano el 2.5.2017, que contempla el procedimiento administrativo en materia de protección al consumidor. Ambas tendrán plena vigencia desde el 15.5.2017. Habrá que estar atentos a sus desarrollos posteriores.
\end{abstract}

Por último, el INDECOPI, previo acuerdo de su Consejo Directivo, puede interponer en la vía judicial procesos relativos a la defensa de los intereses difusos y colectivos de los consumidores, los cuales observarán las prescripciones del Código Procesal Civil, en lo que correspondiera. Las asociaciones de consumidores, de igual manera, pueden interponer tales procesos. Esta segunda vía es también la indicada para la resolución de aquellos casos relacionados a la producción de daños al consumidor, en atención a lo dispuesto por el artículo 100 del CPDC..$^{5}$

\footnotetext{
4 De acuerdo al Decreto Legislativo $\mathrm{N}^{\circ}$ 1308, que modificó el Código de Protección y Defensa del Consumidor; publicado en el diario oficial El Peruano el 30.12.2016 y la Directiva N 005-2017/DIR-COD-INDECOPI, publicada en el diario oficial El Peruano el 28.4.2017.

${ }^{5}$ Dice Espinoza que "la finalidad de la inclusión de este artículo es la de hacer entender que al presentarse un hecho que lesione los derechos de los consumidores, estos tienen expeditas, de manera autónoma y no preclusiva, tanto la vía civil como administrativa (y de ser el caso, penal) para su tutela y protección”. ESPINOZA ESPINOZA, Juan. "La tutela del consumidor en el Perú: una protección en dos escenarios”. En: Actualidad Jurídica, tomo 239, octubre 2013, Lima, p.280.
} 


\section{Revista Eletrônica da Faculdade de Direito da Universidade Federal de Pelotas (UFPel) Dossiê Consumo e Vulnerabilidade: a proteção jurídica dos consumidores no século XXI. Vol. 03, N. 1, Jan-Jun., 2017.}

ISSN - 2448-3303

\section{2) Presentación}

Al cumplirse cuatro años de la vigencia del Código de Protección y Defensa del Consumidor peruano [CPDC], resulta imprescindible efectuar una consolidación de los principales criterios interpretativos establecidos por la Sala Especializada en Protección al Consumidor del Instituto Nacional de Defensa de la Competencia y de la Protección de la Propiedad Intelectual [en adelante, INDECOPI], en los casos vinculados a la calificación legal de consumidor, la situación de los microempresarios, la tutela de los denominados consumidores periféricos, el uso mixto de bienes y servicios, el derecho de información, el deber de idoneidad y discriminación. No niego que existan otros temas de interés, sin embargo, los indicados son los que han generado mayor controversia en la doctrina nacional y sobre los cuales me he pronunciado en su oportunidad, por lo que es necesario volver tras estos pasos para reafirmar o modificar lo dicho, así como evaluar las críticas efectuadas.

Conforme a la Nota del Autor, el presente texto fue terminando, en su versión original, cuando el CPDC contaba con 4 años de vigencia. Al acercarse ya a los 7 años, mucha agua ha corrido bajo el puente, por lo que es necesario dar cuenta, en esta versión actualizada, de las señas más importantes de este periodo reciente.

La defensa de los derechos del consumidor en el Perú se realiza en dos vías distintas: una, de naturaleza administrativa; la otra, de naturaleza civil [sin perjuicio de la penal, cuando el caso lo amerite]. En la primera, tiene competencia el INDECOPI, quien de acuerdo al artículo 105 del $\mathrm{CPDC}^{6}$ constituye la autoridad con competencia primaria y de alcance nacional para conocer las presuntas infracciones a las disposiciones del Código, así como para imponer las sanciones y medidas correctivas que correspondan. Tal se viabiliza por medio de sendos procedimientos administrativos, uno de los cuales, el sumarísimo, está orientado a resolver con celeridad los conflictos suscitados entre los consumidores y proveedores, siempre y cuando la cuantía de los

\footnotetext{
${ }^{6}$ Esta norma fue modificada por el Decreto Legislativo $\mathrm{N}^{\circ} 1308$, publicado en el diario oficial El Peruano el 30.12.2016. El texto citado no ha sufrido variación alguna.
} 


\section{Revista Eletrônica da Faculdade de Direito da Universidade Federal de Pelotas (UFPel) Dossiê Consumo e Vulnerabilidade: a proteção jurídica dos consumidores no século XXI. Vol. 03, N. 1, Jan-Jun., 2017.}

ISSN - 2448-3303

productos y servicios objeto del mismo no sobrepase las 3 Unidades Impositivas Tributarias; ${ }^{7}$ así como para conocer denuncias que versen sobre la falta de atención a reclamos y requerimientos de información, métodos abusivos de cobranza, falta de entrega del producto, con independencia de su cuantía. Del mismo modo, denuncias sobre incumplimiento de medida correctiva, acuerdos conciliatorios y liquidación de costas y costos. El Órgano Resolutivo de Procedimientos Sumarísimos (ORPS), que actúa como primera instancia administrativa, no puede conocer denuncias relativas a reclamos por sustancias o productos peligrosos, discriminación o trato diferenciado, servicios médicos, actos que afecten intereses colectivos o difusos o los que se refieran a productos o servicios que superen la cuantía atrás indicada. Las resoluciones emitidas por este órgano son impugnadas ante la Comisión de Protección al Consumidor o la comisión con facultades desconcentradas, que constituye la segunda instancia administrativa en este procedimiento, cuyas resoluciones agotan la vía, pudiendo ser cuestionadas luego en el Poder Judicial por medio del proceso contencioso-administrativo. ${ }^{8}$

En dicho procedimiento, antes de la expedición del Decreto Legislativo $\mathrm{N}^{\circ} 1308$ que modificó diversos artículos del CPDC [véase nota a pie 1], las resoluciones de la Comisión podían ser elevadas, mediante Recurso de Revisión, a la Sala Especializada en Protección al Consumidor, que solo analizaba cuestiones de puro derecho. Esto se ha suprimido ahora, pero manteniéndose la competencia de la Sala para resolver recursos de apelación derivados de los restantes procedimientos tramitados ante la autoridad administrativa. Hago esta observación porque en las líneas que siguen aparece reiteradamente la mención a dicho medio impugnatorio, por lo que cuando esto ocurra tendrá que recordarse lo anotado precedentemente.

\footnotetext{
Estando en la fase de revisión de estas líneas, aparecen publicadas dos directivas orientadas a normar los procedimientos administrativos en materia de defensa del consumidor. La primera es la Directiva $\mathrm{N}^{\circ}$ 005-2017/DIR-COD-INDECOPI, publicada en el diario oficial El Peruano el 28.4.2017, que regula el procedimiento sumarísimo; y la segunda, la Directiva N $^{\circ}$ 006-2017/DIR-COD-INDECOPI, publicada en el diario oficial El Peruano el 2.5.2017, que contempla el procedimiento administrativo en materia de protección al consumidor. Ambas tendrán plena vigencia desde el 15.5.2017. Habrá que estar atentos a sus desarrollos posteriores.
}

\footnotetext{
${ }^{7}$ La Unidad Impositiva Tributaria [UIT] para el periodo 2014 fue 3800 nuevos soles. Para el año 2017, se la ha fijado en 4050 nuevos soles, según el D.S. N 353-2016-EF, publicado en el diario oficial El Peruano el 22.12.2016. Los montos antes indicados se modifican cada año.

${ }^{8}$ De acuerdo al Decreto Legislativo $\mathrm{N}^{\circ} 1308$, que modificó el Código de Protección y Defensa del Consumidor; publicado en el diario oficial El Peruano el 30.12.2016 y la Directiva N 005-2017/DIR-COD-INDECOPI, publicada en el diario oficial El Peruano el 28.4.2017.
} 


\section{Revista Eletrônica da Faculdade de Direito da Universidade Federal de Pelotas (UFPel) Dossiê Consumo e Vulnerabilidade: a proteção jurídica dos consumidores no século XXI. Vol. 03, N. 1, Jan-Jun., 2017.}

ISSN - 2448-3303

Por último, el INDECOPI, previo acuerdo de su Consejo Directivo, puede interponer en la vía judicial procesos relativos a la defensa de los intereses difusos y colectivos de los consumidores, los cuales observarán las prescripciones del Código Procesal Civil, en lo que correspondiera. Las asociaciones de consumidores, de igual manera, pueden interponer tales procesos. Esta segunda vía es también la indicada para la resolución de aquellos casos relacionados a la producción de daños al consumidor, en atención a lo dispuesto por el artículo 100 del CPDC. ${ }^{9}$

\section{3) Reconocimiento constitucional de la defensa del consumidor}

Ningún discurso en el tema que nos ocupa puede iniciarse si previamente no se revisan las normas constitucionales que, de manera particular, se han referido al consumidor y a la política estatal orientada a su tuición; habida cuenta que de ellas se desprende la regulación existente en los distintos ámbitos donde se ha aplicado.

La historia constitucional de la protección del consumidor en el Perú data desde 1979. Solo a partir de la Carta de ese año es posible encontrar una disposición puntual al respecto; aunque en la precedente de 1933 se aprecien algunas normas vinculadas indirectamente al consumidor, pero sin nombrarlo expresamente. ${ }^{10}$

En efecto, en la segunda parte del artículo 110, incluido en los Principios Generales [Capítulo I] del Régimen Económico [Título III] de la Constitución de 1979, se lee que “[e]1 Estado promueve el desarrollo económico y social mediante el incremento de la producción y de la productividad, la racional utilización de los recursos, el pleno empleo y la distribución equitativa del ingreso", agregando que "fomenta los diversos sectores de la producción y defiende el interés de los consumidores" [cursiva fuera de texto]. Conjuntamente con este numeral, la primera parte del 17 proclamaba que “[e]l Estado reglamenta y supervisa la producción, calidad, uso y comercio de los productos alimenticios, químicos, farmacéuticos y biológicos”, con lo cual

\footnotetext{
${ }^{9}$ Dice Espinoza que "la finalidad de la inclusión de este artículo es la de hacer entender que al presentarse un hecho que lesione los derechos de los consumidores, estos tienen expeditas, de manera autónoma y no preclusiva, tanto la vía civil como administrativa (y de ser el caso, penal) para su tutela y protección". ESPINOZA ESPINOZA, Juan. "La tutela del consumidor en el Perú: una protección en dos escenarios”. En: Actualidad Jurídica, tomo 239, octubre 2013, Lima, p.280.

${ }^{10}$ Así, por ejemplo, los artículos 13 [supervigilancia de entidades bancarias], 16 [prohibición de monopolios, y acaparamientos industriales y comerciales], 39 [tipo de moneda para tarifa de pasajes y fletes], y 50 [cuidado de la salud pública].
} 


\section{Revista Eletrônica da Faculdade de Direito da Universidade Federal de Pelotas (UFPel) Dossiê Consumo e Vulnerabilidade: a proteção jurídica dos consumidores no século XXI. Vol. 03, N. 1, Jan-Jun., 2017.}

ISSN - 2448-3303

se dejaba sentir ya una marcada preocupación por la suerte del consumidor en el mercado respecto a productos específicos.

Bajo el influjo de la Constitución de 1979, se dicta en el país la primera normativa que atenderá especialmente la problemática del consumidor, aunque no con la completitud deseada, ya que su dación se produjo en un ambiente signado por la crisis económica: nos referimos al D.S. $\mathrm{N}^{\circ}$ 036-83-JUS, que contenía medidas extraordinarias en materia económica en defensa del interés de los consumidores.

Tal regulación no supuso, lamentablemente, el establecimiento de un sistema orgánico de protección del consumidor, pues no vino acompañada con la creación de una agencia estatal especializada en la resolución de conflictos entre consumidores y proveedores, ya que la aplicación y monitoreo de dicho dispositivo legal se confió a funcionarios diversos, como los ministros de economía y finanzas, educación, agricultura, pesquería, energía y minas, industria, entre otros; alcaldes; fiscales; autoridades políticas y otros designados por el Poder Ejecutivo. No obstante, debe destacarse la reacción por parte del Estado de articular un conjunto de dispositivos legales en torno a la situación del consumidor.

Pero todavía tendría que esperarse largos años para ver consolidada una regulación importante y, con ella, la puesta en marcha de un auténtico ámbito estatal en materia de consumo. No fue hasta 1991 que se expide una ley ambiciosa, más completa, y que trajo consigo, tiempo después, la conformación de una entidad administrativa encargada no solo de monitorear el mercado, sino de promover procedimientos de oficio y resolver los planteados a instancia del propio consumidor, imponiendo sanciones contra los proveedores que hubieran violentado sus derechos en la adquisición de bienes y servicios. Nos referimos a la Ley de Protección del Consumidor [Dec. Leg. $\mathrm{N}^{\circ}$ 716] y al Instituto Nacional de Defensa de la Competencia y de la Protección de la Propiedad Intelectual, ${ }^{11}$ respectivamente.

Un año más tarde, con la disolución del Parlamento, el cierre del Tribunal de Garantías Constitucionales, la destitución de los magistrados del Poder Judicial, la detención arbitraria de los principales líderes políticos del país, y la orden de muerte para el ex Presidente Alan García Pérez, entre otros acontecimientos, se daría inicio a uno de los periodos más oscuros de la historia peruana, que marcado por la represión, el asesinato y la corrupción sin límites, tuvo como su momento resaltante la aprobación de una nueva Carta Política, en 1993.

\footnotetext{
${ }^{11}$ Esta entidad fue creada en noviembre de 1992, mediante el Decreto Ley $\mathrm{N}^{\circ} 25868$.
} 


\section{Revista Eletrônica da Faculdade de Direito da Universidade Federal de Pelotas (UFPel) Dossiê Consumo e Vulnerabilidade: a proteção jurídica dos consumidores no século XXI. Vol. 03, N. 1, Jan-Jun., 2017.}

ISSN - 2448-3303

Esta Constitución destaca ${ }^{12}$ por no limitarse a declarar que el Estado defiende el interés de los consumidores, sino que procura establecer los principales derechos que le corresponden en el mercado, garantizándolos. Pero también implica colocar al consumidor como eje o centro de la economía nacional. ${ }^{13}$ Declaró en su momento Carlos TORRES y TORRES LARA, Presidente de la Comisión de Constitución del Congreso Constituyente Democrático que dictó dicha Carta Política, que "[1]a Nueva Constitución de 93 traslada el control económico más bien hacia la defensa del consumidor", añadiendo que "[e]1 centro del Derecho Empresarial deja de ser la empresa misma para trasladarse a la relación 'empresa consumidor', que es donde el Estado ahora puede jugar un papel más objetivo". ${ }^{14}$ [sic]

Prescribe su artículo 65 que el Estado defiende el interés de los consumidores y usuarios, garantizando el derecho a la información sobre los bienes y servicios que se encuentran a su disposición en el mercado; velando asimismo, por la salud y seguridad de la población; en una fórmula que no puede considerarse numerus clausus, sino abierta a otros derechos igualmente asegurados. $^{15}$

El Tribunal Constitucional, en la sentencia recaída en el Exp. $\mathrm{N}^{\circ}$ 0008-2003-AI/TC, del 11.11.2003, ha precisado que la Constitución ha estatuido la defensa de los intereses de los consumidores y usuarios por medio de un derrotero jurídico binario, es decir "establece un principio rector para la actuación del Estado y, simultáneamente, consagra un derecho subjetivo. En lo primero, el artículo tiene la dimensión de una pauta básica o postulado destinado a orientar y fundamentar la actuación del Estado respecto a cualquier actividad económica. Así, el juicio estimativo y el juicio lógico derivado de la conducta del Estado sobre la materia, tienen como horizonte tuitivo la defensa de los intereses de los consumidores y los usuarios. En lo segundo, la Constitución reconoce la facultad de acción defensiva de los consumidores y usuarios en los casos

\footnotetext{
${ }^{12}$ Aunque las críticas a ella persistan hasta hoy, al punto de reclamarse -desde diversos sectores de la clase política e intelectual, y algunos juristas- el retorno a la derogada Carta de 1979.

${ }^{13}$ Esta realidad, señala SÁENZ DÁVALOS, Luis. "La defensa del consumidor en el Derecho Constitucional". En: Revista Jurídica del Perú, número 42, Trujillo, 2003, p. 116, tiene entre uno de sus protagonistas al ciudadano común y corriente concebido, no como un ente aislado de los agentes económicos de producción o prestación sino en su relación cotidiana y directa con aquellos. Son en rigor estos últimos los que al proveerle los bienes y servicios que necesita, terminan por convertirlo en un permanente o necesario dependiente, es decir, en un sujeto consumidor. Esta posición de sometimiento del consumidor frente a los agentes dominantes del mercado, añade, fuerza a que el derecho constitucional postule la presencia de una específica obligación estatal, consistente en dotarlo de una adecuada esfera de protección frente a los excesos o abusos generados en el marco de dicha relación.

${ }^{14}$ Cit. RUBIO CORREA, Marcial. Estudio de la Constitución Política de 1993, Fondo editorial de la Pontificia Universidad Católica del Perú, tomo III, Lima, 1999, p. 319.

${ }^{15}$ Cfr. artículo 3, Constitución de 1993.
} 


\section{Revista Eletrônica da Faculdade de Direito da Universidade Federal de Pelotas (UFPel) Dossiê Consumo e Vulnerabilidade: a proteção jurídica dos consumidores no século XXI. Vol. 03, N. 1, Jan-Jun., 2017.}

ISSN - 2448-3303

de transgresión o desconocimiento de sus legítimos intereses; es decir, apareja el atributo de exigir al Estado una actuación determinada cuando se produzca alguna forma de amenaza o afectación efectiva de los derechos de consumidor o usuario [sic], incluyendo la capacidad de acción contra el propio proveedor". 16

En otra oportunidad, el Tribunal Constitucional -en la STC Exp. 3315-2004-AA/TC, del 17.1.2005- ha declarado que tal derrotero jurídico binario definido por la Ley Suprema supone, también, una pluralidad de principios; como el pro consumidor, el de proscripción del abuso del derecho, de isonomia real, de la restitutio in integrum, transparencia, veracidad, in dubio pro consumidor, y el principio pro asociativo.

Aquellos son, por consiguiente, los flancos por donde discurre actualmente la política estatal de defensa del consumidor, a partir de lo dispuesto en el numeral 65 de la Constitución nacional; recogida y desarrollada hoy en día por el Código de Protección y Defensa del Consumidor del año 2010, cuyo artículo I del Título Preliminar declara que se instituye como principio rector de la política social y económica del Estado la protección de los derechos de los consumidores, dentro del marco del citado artículo 65 y del régimen de economía social de mercado asumido por el país, en el numeral $58^{17}$ de la Constitución.

Como correctamente ha señalado un sector de la doctrina, con palabras que hago mías, "se produce en masa, se comercializa en masa, se contrata en masa y, eventualmente, se daña en masa; y en esa lógica, en esa cadena o dinámica, el consumidor no solo tiene un déficit de información, como muchas veces se ha argumentado, sino también un déficit de negociación y de contratación. En realidad, en todo el ítem contractual [sic] del contrato de consumo, el consumidor tiene un déficit y está en una situación de vulnerabilidad y eso es lo que reconoce la Constitución y así tiene que interpretarse...". ${ }^{18}$

\section{4) El alcance de la calificación legal de consumidor.-}

\footnotetext{
${ }^{16}$ Similares argumentos fueron recogidos posteriormente por la STC Exp. № 0858-2003-AA/TC, del 24.3.2004 y por la Resol. recaída en el Exp. Nº5286-2009-PA/TC, del 9.8.2010.

${ }^{17}$ Artículo 58, Constitución.- "La iniciativa privada es libre. Se ejerce en una economía social de mercado. Bajo este régimen, el Estado orienta el desarrollo del país, y actúa principalmente en las áreas de promoción de empleo, salud, educación, seguridad, servicios públicos e infraestructura".

${ }^{18}$ GUTIÉRREZ CAMACHO, Walter. En: Reflexiones a propósito del Código de Protección y Defensa del Consumidor, Quincuagésima reunión INTERCAMPUS, María Matilde Schwalb (editora), Universidad del Pacífico, Lima, 2010 , pp. 30-31.
} 


\section{Revista Eletrônica da Faculdade de Direito da Universidade Federal de Pelotas (UFPel) Dossiê Consumo e Vulnerabilidade: a proteção jurídica dos consumidores no século XXI. Vol. 03, N. 1, Jan-Jun., 2017.}

ISSN - 2448-3303

Uno de los aspectos más delicados y problemáticos del ámbito de defensa del consumidor es, sin hesitación alguna, lo concerniente a la definición de su beneficiario directo. Delicado, por cuanto aquel se restringirá o ensanchará dependiendo del temperamento del legislador de turno; y problemático, porque definidos los contornos de dicho espacio por medio de la regulación especial, habrá que estar a la interpretación que de esta efectúe la autoridad de consumo para saber a ciencia cierta, y en el caso concreto, quién califica o no como tal; es decir, quién constituye o no consumidor, con los riesgos que ello entraña. ${ }^{19}$

El estado de cosas actual, no obstante algunos tropiezos y vaivenes, parece decantarse definitivamente por la amplitud del sistema tutelar que por su estrechez; y esto es particularmente observable en los proyectos legislativos que precedieron al CDPC y, por supuesto, en el texto del Código, que lo irradia generosamente a aquellos sujetos que aun cuando no califiquen stricto sensu como consumidores, se los considera así sobre la base de la observancia de ciertos presupuestos contenidos en la ley.

El CPDC define al consumidor en el artículo IV.1 del Título Preliminar, en los términos siguientes:

\footnotetext{
1. Consumidores o usuarios

1.1 Las personas naturales o jurídicas que adquieren, utilizan o disfrutan como destinatarios finales productos o servicios materiales e inmateriales, en beneficio propio o de su grupo familiar o social, actuando así en un ámbito ajeno a una actividad empresarial o profesional. No se considera consumidor para efectos de este Código a quien adquiere, utiliza o disfruta de un producto o servicio normalmente destinado para los fines de su actividad como proveedor.

1.2 Los microempresarios que evidencien una situación de asimetría informativa con el proveedor respecto de aquellos productos o servicios que no formen parte del giro propio del negocio.

1.3 En caso de duda sobre el destino final de determinado producto o servicio, se califica como consumidor a quien lo adquiere, usa o disfruta.
}

Se tutela tanto a las personas naturales como jurídicas que adquieran, utilicen o disfruten como destinatarios finales productos o servicios. El dispositivo mejora sustancialmente la definición contenida en la derogada Ley Complementaria del Sistema de Protección al Consumidor [Dec. Leg. $\mathrm{N}^{\circ}$ 1045], que modificó a su vez la existente en la Ley de Protección al

\footnotetext{
${ }^{19}$ Enseña Lima Marques que el gran desafío del intérprete y aplicador de la ley es saber diferenciar y saber "ver" quién es comerciante, ciudadano, consumidor, proveedor, quién hace parte de la cadena de producción y de distribución y quién retira el bien del mercado como destinario final, y quién está equiparado a este. LIMA MARQUES, Claudia. "Campo de Aplicação do CDC". En: BENJAMIN, Antonio Herman V., Claudia LIMA MARQUES y Leonardo ROSCOE BESSA, Manual de Direito do Consumidor, Revista dos Tribunais, $6{ }^{\text {ta. }}$ edicão [revista, atualizada e ampliada], São Paulo, 2014, p.95. [Traducción libre].
} 


\section{Revista Eletrônica da Faculdade de Direito da Universidade Federal de Pelotas (UFPel) Dossiê Consumo e Vulnerabilidade: a proteção jurídica dos consumidores no século XXI. Vol. 03, N. 1, Jan-Jun., 2017.}

ISSN - 2448-3303

Consumidor. Dicha Ley Complementaria, inexplicablemente dejó fuera a las personas jurídicas, al establecer que solo eran considerados consumidores "[1]as personas naturales que, en la adquisición, uso o disfrute de un bien o contratación de un servicio, actúan en un ámbito ajeno a una actividad empresarial o profesional...”, y, excepcionalmente, los microempresarios, sobre los cuales volveré más adelante. ${ }^{20}$

Ello es así, porque la disposición objeto de reforma textualmente prescribía que eran consumidores las personas naturales $y$ jurídicas, ${ }^{21}$ con lo cual la cobertura del sistema era realmente importante. A pesar de este error, calificada doctrina nacional señaló que una interpretación pro consumidor debía conducir a la inclusión de estas últimas dentro de la categoría a fin de evitar una "absurda discriminación", 22 crítica que desde luego era atendible, sin reservas.

Finalmente se apela al filtro del destino final de la adquisición, uso y disfrute de los bienes y servicios, a partir de una actuación en un ámbito ajeno a una actividad empresarial o profesional. Estamos ante el destino final de un producto o servicio cuando no se los reintroduce al mercado para el ejercicio de una actividad económica puntual; con otras palabras, cuando el bien o servicio "muere" con el consumidor.

De otro lado, el CPDC exige que se actúe en un ámbito ajeno al de una actividad empresarial o profesional, en atención a que tales actividades constituirían las vías mediante las cuales esos productos se reinsertan a un proceso económico particular. Desde luego, la autoridad de consumo deberá tener cuidado cuando se enfrente a situaciones problemáticas, que podrían traer como consecuencia la exclusión de ciertas personas del ámbito tutelar; pues a pesar que se actúe dentro de la órbita empresarial o profesional, ciertos productos y servicios no alcanzarán a reinsertarse en el circuito económico, dada la naturaleza y propósito de su adquisición.

\section{1) Los microempresarios como consumidores y los servicios transversales.}

Los microempresarios constituyen también sujetos protegidos por el CPDC. Ahora de manera amplia y no excepcional como se planteó en la Ley de Protección al Consumidor, fruto de

\footnotetext{
${ }^{20}$ Analizamos el tema en CARRANZA ÁLVAREZ, César. "El nuevo perfil del consumidor en la legislación peruana". En: Revista de Derecho de la Competencia, Facultad de Ciencias Jurídicas de la Pontificia Universidad Javeriana, volumen 5, número 5, enero-diciembre 2009, Bogotá, pp. 107-132.

${ }^{21}$ Así, el artículo 3 a) del D.S. N 039-2000-ITINCI, TUO de la Ley de Protección al Consumidor.

22 ESPINOZA ESPINOZA, Juan. "Primeras reflexiones a propósito del Código de Protección y Defensa del Consumidor". En: Actualidad Jurídica, tomo 202, setiembre 2010, Lima, p.16.
} 


\section{Revista Eletrônica da Faculdade de Direito da Universidade Federal de Pelotas (UFPel) Dossiê Consumo e Vulnerabilidade: a proteção jurídica dos consumidores no século XXI. Vol. 03, N. 1, Jan-Jun., 2017.}

ISSN - 2448-3303

su reforma por la Ley Complementaria del Sistema de Protección al Consumidor de 2008, referida. Actualmente son tutelados siempre y cuando evidencien una situación de asimetría informativa con el proveedor, respecto de aquellos productos y servicios que no formen parte del giro propio del negocio [art. IV, 1.2].

De acuerdo con el artículo 5 del Texto Único Ordenado de la Ley de Impulso al Desarrollo Productivo y al Crecimiento Empresarial, son microempresarios los que tengan exclusivamente ventas anuales hasta un monto máximo de 150 unidades impositivas tributarias. Si bien el CPDC contempla la expresión microempresarios, esta debe entenderse ampliamente en el sentido de microempresa, caracterizada por aquella última norma como "la unidad económica constituida por una persona natural o jurídica, bajo cualquier forma de organización o gestión empresarial contemplada en la legislación vigente, que tiene como objeto desarrollar actividades de extracción, transformación, producción, comercialización de bienes o prestación de servicios" [art. 4]. ${ }^{23}$

Precisamente, en el caso Aero Servicios S.A.C. c. Euroshop S.A. [Resol. $\mathrm{N}^{\circ}$ 07422013/SPC-INDECOPI, del 25.3.2013], la Sala señaló que tratándose de los microempresarios, para amparar cualquier denuncia, debían considerarse tres aspectos, a saber: [i] que el denunciante sea, en verdad, un microempresario, [ii] que el producto o servicio no se encuentre relacionado que no forme parte, en estricto- al giro propio de su negocio, y [iii] que se encuentre en una situación de asimetría informativa con el proveedor.

En este caso, la denunciante adquirió un vehículo de la marca Volkswagen, pero al poco tiempo presentó fallas, por lo que se le tuvo que internar en un taller de reparación, luego de lo cual solicitó a la empresa vendedora su cambio, no siendo atendida. Al resolver la denuncia, la Comisión de Protección al Consumidor de Lima Sur declaró su improcedencia porque se había acreditado que la denunciante tenía un volumen de ventas superior a máximo legal exigido [150 UITs], por lo que no calificaba como consumidora de acuerdo al CPDC. Aun cuando en su recurso de apelación la denunciante señaló que no se había observado su calidad de microempresaria, pues contaba con 4 trabajadores [requisito exigido en su momento por la legislación de la materia], la Sala confirmó la decisión anterior, precisamente porque la empresa denunciante no calzaba dentro de la noción de consumidor del artículo IV,1.2 del Código.

\footnotetext{
${ }^{23}$ No obstante esta precisión, utilizaremos la expresión que aparece en el Código.
} 


\section{Revista Eletrônica da Faculdade de Direito da Universidade Federal de Pelotas (UFPel) Dossiê Consumo e Vulnerabilidade: a proteção jurídica dos consumidores no século XXI. Vol. 03, N. 1, Jan-Jun., 2017.}

ISSN - 2448-3303

La norma exige, además, que se evidencie una situación de asimetría informativa respecto de aquellos productos y servicios que no formen parte del giro del negocio del microempresario. Veamos la interpretación que de esta última expresión ha efectuado la autoridad de consumo.

Se recordará que la noción de consumidor existente hasta la entrada en vigencia del CPDC, establecía que eran consumidores, excepcionalmente, "los microempresarios que evidencien una situación de asimetría informativa con el proveedor respecto de aquellos productos o servicios no relacionados con el giro propio del negocio". El Código ha suprimido la excepcionalidad y dispuesto que tales productos y servicios no formen parte del giro del negocio del microempresario, para declararlo como tal.

En el caso Representaciones y Servicios A \& M.E.I.R.L. c. Yell Perú S.A.C. [Resol. № 2188-2011/SC2-INDECOPI, del 18.8.2011], resuelto bajo el amparo de la derogada Ley de Protección al Consumidor estando ya vigente el CPDC, la Sala de Defensa de la Competencia N $^{\circ}$ 2 [hoy, Sala Especializada en Protección al Consumidor] precisó que "son productos o servicios relacionados con el giro propio el negocio (aparte de los productos y servicios ofrecidos por el propio microempresario en el mercado) aquellos inherentes a la actividad económica desarrollada por el microempresario, esto es, absolutamente imprescindibles para que la misma se desenvuelva", citando entre ellos a la materia prima y/o materiales fabricados que sirven de insumos para elaborar otros productos, y las maquinarias o instrumental necesarios para prestar determinados servicios [cursivas originales]. En ese sentido, interpretó que los productos y servicios no relacionados con el negocio del microempresario serán todos aquellos que, aunque complementarios a su actividad, amén de facilitarla, no son absolutamente imprescindibles para su desarrollo.

Similar criterio es ahora aplicado para establecer el alcance de la expresión "productos y servicios que no formen parte del giro propio del negocio" del microempresario. En Agropecuaria Vereau S.A.C. c. Weilenmann \& CIA S.A.C. [Resol. $\mathrm{N}^{\circ}$ 3590-2012/SPC-INDECOPI, del 11.12.2012], la denunciante señaló que los productos adquiridos de la empresa denunciada para el cuidado de su ganado vacuno -Lactacid y U-20 No DRIP- habían ocasionado irritaciones e incidencia de mastitis, generándole perjuicios económicos. Del mismo modo, señaló que los productos contenían información falsa pues no provenían de Argentina. De acuerdo con lo que aparecía en la denuncia, la empresa se dedicaba a la crianza de ganado vacuno, utilizando los productos para el cuidado de sus vacas luego del proceso de ordeño. En la partida registral 


\section{Revista Eletrônica da Faculdade de Direito da Universidade Federal de Pelotas (UFPel) Dossiê Consumo e Vulnerabilidade: a proteção jurídica dos consumidores no século XXI. Vol. 03, N. 1, Jan-Jun., 2017.}

ISSN - 2448-3303

aportada al procedimiento, se apreciaba que su objeto social era la producción y comercialización de leche y productos lácteos y la comercialización de ganado, ambos al por mayor y menor.

$\mathrm{Al}$ analizar la apelación interpuesta por dicha empresa contra la resolución de la Comisión de Protección al Consumidor, sede Lima Sur $\mathrm{N}^{\circ} 2$, que declaró improcedente la denuncia por no calificar como consumidora [los productos adquiridos formaban parte del giro de negocio], la Sala concluyó que dichos productos fueron destinados para el proceso de crianza y producción de leche, por lo que cabía concluir que formaban parte de la actividad realizada por la denunciante; añadiendo que cuando un microempresario adquiere productos y servicios que forman parte del giro de su negocio, posee o debe poseer conocimientos especializados respecto de su adquisición, superiores a los de un consumidor final promedio y más bien cercanos a los del proveedor, en tanto los productos se encuentran intrínsecamente relacionados con su actividad empresarial, pues son absolutamente necesarios para su desarrollo. En este sentido, la Sala confirmó la decisión de la instancia.

En el caso Marisol Martina Aréstegui Otazu c. Petroleum Gas Company S.A. [Resol. № 2915-2014/SPC-INDECOPI, del 1.9.2014], la Sala entendió que el bien objeto de controversia no podía considerarse vinculado a la actividad empresarial de la denunciante. En efecto, esta contrató la instalación de un equipo GPS para su automóvil, que utilizaba para el servicio de taxi, el cual efectuaría su monitoreo durante las 24 horas de los 365 días del año, para rastrearlo y localizarlo. Poco después, el vehículo fue robado, y luego de algunos meses se le informó que el equipo había sido bloqueado por lo que era imposible su ubicación. La señora Aréstegui entendió que el servicio prestado no era idóneo.

Tramitado bajo las pautas del procedimiento sumarísimo, en primera como en segunda instancia la denuncia fue declarada improcedente, al considerarse que el equipo GPS estaba vinculado de manera indesligable al emprendimiento empresarial de la denunciante. $\mathrm{Al}$ resolver el recurso de revisión planteado por la afectada, la Sala interpretó el alcance del numeral 1.2 del artículo IV del Título Preliminar del CPDC, ${ }^{24}$ en los términos siguientes: [i] como premisa general, indicó que el requisito habilitante para la calificación de consumidor del microempresario es que los productos y servicios que adquiera no sean imprescindibles para su actividad en el mercado; [ii] luego, aplicándola al caso, precisó que el equipo GPS no representa una condición inherente en un negocio de prestación del servicio de taxi, y menos exige su incorporación al

\footnotetext{
${ }^{24}$ Remitimos al texto de este artículo anotado páginas atrás.
} 


\section{Revista Eletrônica da Faculdade de Direito da Universidade Federal de Pelotas (UFPel) Dossiê Consumo e Vulnerabilidade: a proteção jurídica dos consumidores no século XXI. Vol. 03, N. 1, Jan-Jun., 2017.}

ISSN - 2448-3303

proceso productivo de dicho rubro, "limitándose a ser una herramienta tecnológica a efectos de su ubicación satelital"; y finalmente, [iii] cuestionó que la Comisión se haya limitado a analizar la actividad económica realizada por la denunciante, cuando lo relevante era determinar si el producto que adquirió era o no imprescindible para la actividad ejercida en el mercado. Con estos argumentos, declaró fundado el recurso, declarándose procedente la denuncia y ordenándose que el órgano de primera instancia [Órgano Resolutivo de Procedimientos Sumarísimos $N^{\circ}$ 3] proceda al trámite correspondiente y emita pronunciamiento sobre el fondo de la controversia.

En síntesis: el criterio informante respecto al requisito que expongo queda direccionado en el sentido de productos y servicios que son complementarios o facilitadores del negocio del microempresario, pero no inherentes o absolutamente imprescindibles para su concreción.

No obstante, la aplicación de este criterio no es pacífica tratándose de los denominados servicios transversales. En el caso que revisamos líneas atrás-Representaciones y Servicios A \& M.E.I.R.L. c. Yell Perú S.A.C, que dio lugar a la Resolución № 2188-2011/SC2-INDECOPI, del 18.8.2011-, que versaba sobre la contratación del servicio de publicidad -la denunciante firmó en blanco el contrato, acordándose con el dependiente que se plasmaría en el documento lo conversado verbalmente; sin embargo, se consignó un precio y un servicio [anuncios por internet] distintos a los pactados- la Sala procedió a variar la interpretación que, hasta entonces, mantenía, según la cual, determinados servicios -como los de publicidad, transporte de mercaderías y financiamiento- deben considerarse transversales a todo esquema productivo o de comercialización y, por tal razón, connaturales [relacionados] al giro propio de tales negocios, no existiendo asimetría informativa en estos casos, incluso si se trata de un microempresario. ${ }^{25}$ Con la nueva pauta, se asume que estos servicios no se encuentran relacionados al giro del negocio del microempresario, existiendo respecto a ellos asimetría informativa con el proveedor, y que aun cuando puedan facilitar la actividad de aquel, no son imprescindibles para su desarrollo.

Un sector de la doctrina nacional ha cuestionado esta novedosa postura. Se expone que "[p]roteger a los microempresarios de los llamados servicios transversales incentiva a que estos finalmente no asuman costos de búsqueda en mayor y en especial mejor calidad de información al

\footnotetext{
${ }^{25}$ Pueden revisarse las Resoluciones N ${ }^{\circ}$ 737-2008/TDC-INDECOPI, El Otro Gramadal S.R.L. c. Yell Perú S.A.C., del 14.4.2008; 1172-2008/TDC-INDECOPI, Asociación Civil Vida Mujer c. Yell Perú S.A.C., del 19.6.2008; 23212010/SC2-INDECOPI, Maderera del Norte S.R.L. c. Banco Continental S.A., del 18.10.2010, en las cuales se desarrolla tal criterio.
} 


\section{Revista Eletrônica da Faculdade de Direito da Universidade Federal de Pelotas (UFPel) Dossiê Consumo e Vulnerabilidade: a proteção jurídica dos consumidores no século XXI. Vol. 03, N. 1, Jan-Jun., 2017.}

ISSN - 2448-3303

momento de contratar", y que en vez de profesionalizarse "se conviertan en 'seudoconsumidores' que no logran internalizar los costos de competir y, con ello, desarrollar sus actividades dentro de la dinámica del mercado". ${ }^{26}$

Dilucidar si estos servicios se relacionan o no -o hacen parte o no, de acuerdo a la expresión utilizada por el CPDC- al giro del negocio del microempresario, es una cuestión que no es fácil resolver, porque en muchos casos la frontera que separa estas dos posibilidades tenderá a acortarse considerablemente. Un microempresario que requiera abrirse campo en el competitivo mercado local o nacional, necesariamente deberá apelar a la contratación de publicidad -ya sea escrita, radial, televisiva o vía internet- si aspira obtener clientes para sus productos o servicios, pues de lo contrario estará condenado a desaparecer pronto del comercio. De igual forma, uno dedicado al rubro de la confección y comercialización de calzado, si pretende consolidarse en el mercado, mejorando sus procesos productivos y la calidad de sus productos, amén del ingreso a otras plazas comerciales, tendrá que optar por el financiamiento bancario si no quiere ver mermada su posibilidad de crecimiento empresarial. Lo mismo podría decirse de la contratación de transporte por parte de quien requiere este servicio para la mejora del proceso de distribución de sus productos. Entonces, ¿cómo distinguir si estos servicios son complementarios a su actividad, o resultan inherentes o absolutamente imprescindibles?, ¿cómo determinar su grado de información sobre tales servicios, en camino a definir su condición de consumidor?, ¿puede asumirse, como regla informante, que estos servicios solo resultan complementarios o facilitadores del emprendimiento de este actor del mercado?

El ejercicio cotidiano de la actividad empresarial convierte al microempresario en un sujeto especializado en todo lo que se vincule al objeto de su negocio. Si se parte de la premisa que en innumerables ocasiones deberá contratar tales servicios, por las necesidades del emprendimiento y las exigencias del mercado, parece que esa contratación reiterada haría que su nivel informativo prácticamente supere al de un consumidor promedio y próximo al del proveedor, por lo que no se cumpliría el presupuesto normativo de la asimetría informativa. Por esta razón, la autoridad de consumo deberá proceder con cuidado, por medio de un análisis particular y detenido de cada caso, pues se corre el peligro que por la vía de la generalización se comprenda como consumidores a quienes por su capacidad informativa no deben merecer esta calificación. Desde luego, no se trata de negar protección a los microempresarios, pues siempre

\footnotetext{
${ }^{26}$ ROJAS KLAUER, Carlos. "La microempresa y su consolidación como consumidor final. Gregorio E.I.R.L.”. En: Diálogo con la Jurisprudencia, número 158, noviembre 2011, Lima, p. 67.
} 


\title{
Revista Eletrônica da Faculdade de Direito da Universidade Federal de Pelotas (UFPel) Dossiê Consumo e Vulnerabilidade: a proteção jurídica dos consumidores no século XXI. Vol. 03, N. 1, Jan-Jun., 2017.
}

ISSN - 2448-3303

queda la posibilidad de recurrir a la vía judicial; sino de ser escrupulosos al momento de evaluar los requisitos que habilitan la entrada al ámbito administrativo de protección al consumidor.

\begin{abstract}
El transcurso del tiempo no ha hecho variar la posición asumida en las líneas precedentes. Como entonces, sigue siendo difícil resolver la problemática derivada de la contratación de estos servicios. Es posible que se argumente que aunque se los contrate regularmente, de igual forma el microempresario estará en una situación de déficit informativo dada la complejidad de los términos que suelen utilizarse en dichos ámbitos del mercado [la reiterada interacción de una persona con una entidad bancaria, no la convierte en una "experta" en banca, p.e.], por lo que aún en estos supuestos merece la calificación de consumidor. De ahí la exigencia a la autoridad, que formulo nuevamente.
\end{abstract}

Para concluir: conforme al contenido normativo del numeral del que vengo dando cuenta, la protección que se dispensa a dicho actor del mercado viene dada por el estado de asimetría informativa que padece con relación al proveedor, respecto a bienes y servicios que no formen parte de su actividad. La Sala, en pronunciamientos anteriores, estableció que en esta hipótesis debe presumirse iuris tantum la existencia de asimetría informativa, quedando a cargo del proveedor la prueba de demostrar que el consumidor sí contaba con conocimientos especializados al tiempo de su adquisición. ${ }^{27}$ Una nueva interpretación de la autoridad ha reemplazado dicha presunción por una iuris et de iure, con lo cual el procedimiento estará encaminado, por lo menos en un primer tramo, a corroborar su estatus de microempresario y la naturaleza de los productos y servicios adquiridos, es decir, si son inherentes o absolutamente imprescindibles o no para su negocio, en camino a su calificación como sujeto tutelado; no siendo posible que el denunciado aporte prueba para desvirtuarla. En este sentido, el caso Marisol Martina Aréstegui Otazu c. Petroleum Gas Company S.A., revisado.

En un caso reciente [Resolución $\mathrm{N}^{\circ}$ 0243-2017/SPC-INDECOPI, del 17.1.2017, Lorena Ruth Jurado de los Reyes Quiñones de Vilca c. Jousi Aymerrit Delgado Cangalahua y otro], la Sala ha precisado que "respecto de los productos y servicios que no forman parte del giro propio del negocio del microempresario denunciante, se presume que este se encuentra en asimetría informativa frente al correspondiente proveedor; sin perjuicio de que dicho proveedor pueda acreditar lo contrario", con lo cual vuelve a insistirse en una presunción iuris tantum, proceder distinto al advertido en la resolución citada en la parte final del párrafo precedente, en la cual señaló que "[d]e otro lado, cabe señalar que esta Sala ha señalado que respecto de los productos y servicios de carácter complejo que no forman parte del giro propio del negocio del microempresario denunciante, se presume sin admitir prueba en contrario que este no cuenta con conocimientos especializados respecto e dicho producto, es decir, se encuentra en asimetría informativa frente al correspondiente proveedor". (sic) Adviértase que se alude en esta última cita a "productos y servicios de

\footnotetext{
${ }^{27}$ Resolución N ${ }^{\circ}$ 2188-2011/SPC-INDECOPI [considerando 41] citada; y Resolución N 3590-2012/SPC-INDECOPI, del 11.12.2012 [considerando 14].
} 


\section{Revista Eletrônica da Faculdade de Direito da Universidade Federal de Pelotas (UFPel) Dossiê Consumo e Vulnerabilidade: a proteção jurídica dos consumidores no século XXI. Vol. 03, N. 1, Jan-Jun., 2017.}

ISSN - 2448-3303

carácter complejo que no forman parte del giro propio del negocio del microempresario", con lo cual parecería existir bienes y servicios que no ostentan este atributo [no complejos], pero que igual no hacen parte del giro empresarial de los microempresarios. Mi pesquisa jurisprudencial, lamentablemente, no ha encontrado la diferenciación entre estos dos supuestos.

\section{2) El consumidor periférico}

Uno de los contenidos más importantes del CPDC es la ampliación del manto protectorio estatal a aquellas personas que, no constituyendo propiamente consumidores de acuerdo al numeral IV.1, igual pueden verse afectados en el mercado; sea porque se encuentran comprendidos o expuestos a una relación de consumo, o en una etapa previa a esta. Es el caso de los que aquí denomino consumidores periféricos [precisamente porque giran en torno a ella] o equiparados, como un sector de la doctrina prefiere.

Dispone el Código que se "protege al consumidor, se encuentre directa o indirectamente expuesto o comprendido por una relación de consumo o en una etapa preliminar a ésta" [art. III.1, TP]. Esta disposición ha dado lugar a una rica jurisprudencia en la cual es posible advertir los derroteros seguidos por la Sala en la aplicación plena de la norma; y a la dación de la Ley $\mathrm{N}^{\circ}$ 30200, del 28.5.2014, cuyo fin es promover el auxilio oportuno de las personas que se encuentren en circunstancia de una condición repentina o inesperada que requieran atención inmediata al poner en peligro inminente su vida. Y esas personas no son más que los consumidores periféricos aludidos precedentemente, según indicación de la propia norma.

La Ley $\mathrm{N}^{\circ} 30200$ se reglamentó 2 años después por medio del Decreto Supremo $\mathrm{N}^{\circ} 018$ 2016-SA, que aprueba el Reglamento de la Ley $\mathrm{N}^{\circ} 30200$, publicado en el diario oficial El Peruano el 14.4.2016, en el cual se contemplan las condiciones y supuestos para la atención en los establecimientos y centros comerciales, así como se precisan los insumos mínimos y equipamiento con el cual deberán contar para la atención de los eventos ocurridos en su interior.

Uno de los primeros casos en los cuales se aplicó la norma anotada, fue el de Francisca Paula Vásquez de Liñán c. Cooperativa de Ahorro y Crédito de los Trabajadores de Sider Perú y otras [Resol. N 0249-2012/SC2-INDECOPI, del 26.1.2012], con un resultado poco feliz. Lo digo de esta forma, porque de la revisión de los antecedentes legislativos del CPDC y de sus normas 


\section{Revista Eletrônica da Faculdade de Direito da Universidade Federal de Pelotas (UFPel) Dossiê Consumo e Vulnerabilidade: a proteção jurídica dos consumidores no século XXI. Vol. 03, N. 1, Jan-Jun., 2017.}

ISSN - 2448-3303

puntuales, no cabía duda alguna que el propósito del legislador se decantaba por una ampliación generosa de su ámbito subjetivo en lugar de su acortamiento. ${ }^{28}$

En el caso, la señora Vásquez solicitó un préstamo de dinero a la denunciada. Esta le entregó solo una parte del mismo. La entidad condicionó la entrega del dinero a que la denunciante aceptara como garante a otra persona [un desconocido], y que a su vez garantizara el préstamo que esta había solicitado. Al poco tiempo, la cooperativa procedió a descontarle de su cuenta el monto de su préstamo y el correspondiente a tal sujeto, aduciendo que el descuento se hacía en virtud a su calidad de fiadora. La denunciante jamás llegó a conocer al sujeto garantizado y menos se le entregó documento alguno que corroborara su estado de garante. En ambas instancias - del procedimiento sumarísimo- se le dio la razón por cuanto no se le entregó el contrato donde ella aparecía como fiadora, imponiéndose a la denunciada una multa de 3 UIT.

Al plantearse recurso de revisión ante la Sala, la denunciada cuestionó particularmente la interpretación hecha por la Comisión de la Oficina Regional del INDECOPI-La Libertad, que consideró que los garantes de deudas ajenas [los fiadores] sí califican como consumidores de acuerdo con el CPDC. Lamentablemente la Sala no siguió este parecer. En efecto, resolvió que debido a que los fiadores no adquieren ningún producto o servicio del proveedor [en este caso, una cooperativa], no pueden ser considerados consumidores, porque su único papel es garantizar la obligación del deudor frente al caso de incumplimiento; deudor que, por cierto, sí califica como consumidor. Dijo la Sala que "[e]l fiador o garante es un tercero ajeno a la relación de consumo, que interviene en el contrato para garantizar las obligaciones del consumidor. Es el consumidor que a cambio del servicio financiero paga la contraprestación a que se refiere el citado numeral 5 del artículo IV". ${ }^{29}$

He cuestionado esta interpretación ${ }^{30}$ porque a partir de una lectura sistemática de los artículos III.1 y IV.5, concordante con el IV.1 del Código, no cabía hesitación alguna en cuanto a la ampliación actual de su ámbito subjetivo, que permite tener como consumidores a quienes no haciendo parte de una relación de consumo con un proveedor, igual se perjudican por las consecuencias que de ese vínculo pueden generarse, como sucede con el fiador que se ve

\footnotetext{
${ }^{28}$ Desarrollamos este tema en CARRANZA ÁLVAREZ, César. “¿Son consumidores los garantes de deudas ajenas? Notas a una reciente resolución del Indecopi”. En: Revista Jurídica del Perú, número 138, agosto 2012, Lima, pp. 299318.

${ }^{29}$ Dispone este numeral: "5. Relación de consumo.- Es la relación por la cual un consumidor adquiere un producto o contrata un servicio con un proveedor a cambio de una contraprestación económica. Esto sin perjuicio de los supuestos contemplados en el artículo III".

${ }^{30}$ CARRANZA ÁlVAREZ, César. “SSon consumidores los garantes de deudas ajenas?”, cit., p. 317.
} 


\section{Revista Eletrônica da Faculdade de Direito da Universidade Federal de Pelotas (UFPel) Dossiê Consumo e Vulnerabilidade: a proteção jurídica dos consumidores no século XXI. Vol. 03, N. 1, Jan-Jun., 2017.}

ISSN - 2448-3303

sometido al cobro indebido de una deuda ya cancelada, que podría involucrar métodos prohibidos de cobranza; a la negativa de brindarle información sobre la deuda que le permita su defensa frente a un cobro injustificado; o el reporte a una central de riesgo, que prácticamente le cerraría las puertas del sistema bancario y financiero, como bien se declaró en el voto en discordia de la resolución comentada, que contrario al pensamiento de la mayoría de la Sala, comprendió correctamente el sentido actual de las normas del CPDC en cuanto a la noción de consumidor se refiere.

No pasaría mucho tiempo para que ese criterio fuera dejado de lado por la Sala, esta vez con una nueva conformación. En Guido Gelacio Sumarriva Valenzuela c. Caja Municipal de Ahorro y Crédito de Arequipa S.A. [Resol. N²721-2012/SC2-INDECOPI, del 11.9.2012], el denunciante señaló que calificaba como consumidor debido a que garantizó una obligación que luego de contraída sufrió retraso en el cumplimiento, afectando su imagen personal. En esta oportunidad, la Sala, en contra de lo afirmado por el Órgano Resolutivo de Procedimientos Sumarísimos y la Comisión de la Oficina Regional del INDECOPI del Cusco [que negaron dicha condición debido a que no se verificó la contratación de algún producto o servicio de la denunciada por parte del denunciante], señaló que existen situaciones excepcionales en las que aun cuando no se establezca una relación de consumo con el denunciante, apelando a una interpretación pro consumidor debe calificársele como consumidor por encontrarse expuesto indirectamente a los efectos de una relación de consumo. Por ello, recogiendo lo dicho en el voto en discordia de la Resolución del caso anterior [en concreto, las consecuencias anotadas], entendió que los garantes son consumidores, poniendo en juego el principio pro consumidor y la interpretación correcta del artículo III.1 del CPDC. ${ }^{31}$

Este temperamento se ha mantenido en otros casos, como los referentes al de aquellas personas que reciben en su domicilio notificaciones de cobro de deudas ajenas y al seguro de responsabilidad civil. En cuanto a los primeros, la Sala ha mantenido la línea interpretativa imperante en cuanto a atribuir la calidad de consumidor no solo a quien establece una relación de consumo con el proveedor de productos y servicios, sino a todo aquel que de alguna u otra manera pueda sufrir los efectos de una en particular, dada su exposición, o por encontrarse comprendido o

\footnotetext{
31 Véase CARRANZA ÁlVAREZ, César. “¡Cambio de rumbo! Los garantes de deudas ajenas y su condición de consumidores”. En: Actualidad Jurídica, tomo 227, octubre 2012, Lima, p. 268.
} 


\section{Revista Eletrônica da Faculdade de Direito da Universidade Federal de Pelotas (UFPel) Dossiê Consumo e Vulnerabilidade: a proteção jurídica dos consumidores no século XXI. Vol. 03, N. 1, Jan-Jun., 2017.}

ISSN - 2448-3303

en una fase anterior a ella; debiéndose entender las normas de tutela del consumidor en sentido lato, de manera particular en lo atinente a la noción de consumidor. ${ }^{32}$

No obstante su reconocimiento como consumidores, tales personas aún mantienen un alto grado de indefensión a partir de la interpretación efectuada por la Sala del artículo 40 del Código Civil, que impide a las instituciones bancarias y financieras suspender el envío de estas notificaciones de cobranza, incluso conociendo que el lugar de destino no es el correcto, mientras el deudor no comunique el cambio de domicilio [donde residió temporalmente y al cual llegan las notificaciones con perjuicio del propietario]. Este cuestionable criterio de la Sala, derivado del caso Marco Antonio Celestino Arroyo c. Banco GNB Perú S.A. [Resol. N ${ }^{\circ}$ 2377-2014/SPCINDECOPI, del 21.7.2014], no solo perjudica a los propietarios que deberán seguir soportando en sus viviendas cobranzas ajenas, atentándose además contra su tranquilidad, armonía familiar y reputación en el círculo social en el cual se desenvuelven; sino también a los que residen temporalmente en viviendas de otros, que requieren la contratación de productos y servicios bancarios, pues a la luz de este parecer de la autoridad de consumo, ningún propietario va a permitir que se utilice en adelante su dirección domiciliaria si de antemano conoce los innumerable inconvenientes a los que puede verse sometido frente a una variación no comunicada oportunamente a la empresa acreedora, por obra de quien la utiliza, y más si frente a un reclamo en ese sentido, solo obtendrá como respuesta el mantenimiento del hecho objeto de denuncia. ${ }^{33} \mathrm{Al}$ final, todo lo avanzado termina por desvanecerse con pronunciamientos de este tipo.

Finalmente, son también consumidores periféricos las víctimas o beneficiarios de un seguro, en particular el de responsabilidad civil. En Carlos Jonathan Pérez Diaz c. Empresa de Transporte Turístico Olano S.A. - Jef Corredores de Seguros S.A.C. [Resol. N 1723-2014/SPCINDECOPI, del 27.5.2014], el denunciante expresó que el bus en el que viajaba fue asaltado por delincuentes sufriendo la pérdida de sus pertenencias y, entre otros reclamos, señaló que si bien la corredora de seguros le indicó el monto a cobrar por la pérdida, nunca lo recibió, por lo que reclamó a esta empresa no siendo atendido. En este extremo, la Comisión de la Oficina Regional del INDECOPI de Arequipa [Resol. N 578-2013/INDECOPI-AQP], declaró improcedente la denuncia por no existir una relación de consumo entre el denunciante y la empresa Jef Corredores

\footnotetext{
${ }^{32}$ Considerando 24 de la Resolución N 0951-2013, del 18.4.2013, Alex Sergio Raymundo Navarro c. Mibanco - Banco de la Microempresa. Este caso tiene como antecedente directo el de Jorge Francisco Pinto Rossi c. BBVA Banco Continental S.A. - Consorcio Réditos S.A.C., resuelto por Resolución Nº 0641-2013/SPC-INDECOPI, del 14.3.2013.

${ }^{33}$ Comentamos la decisión en CARRANZA ÁLVAREZ, César. "De nuevo sobre las notificaciones de cobro remitidas a terceros”. En: Diálogo con la Jurisprudencia, número 193, octubre 2014, Lima, pp. 293-297.
} 


\section{Revista Eletrônica da Faculdade de Direito da Universidade Federal de Pelotas (UFPel) Dossiê Consumo e Vulnerabilidade: a proteção jurídica dos consumidores no século XXI. Vol. 03, N. 1, Jan-Jun., 2017.}

ISSN - 2448-3303

de Seguros S.A.C. Nada debe reprocharse a la Sala que con buen criterio concluyó que no es óbice para considerar consumidor a la víctima de un robo el que no sea parte del contrato de seguro suscrito entre el asegurado y la empresa de seguros [que no era la empresa contra la cual se interpuso la denuncia], pues en último término resulta ser su beneficiario y por ello puede afectarse con el incumplimiento de las obligaciones por parte de la compañía aseguradora, o de la encargada del corretaje de seguros, agregamos, como era en este caso particular. Entre otros argumentos, la Sala interpretó que "la víctima (tercero perjudicado) hoy debe ser considerado como un consumidor de seguros, dado que el seguro (especialmente el de responsabilidad civil frente a terceros) tiene dos consumidores. Uno de esos consumidores es el propio asegurado, y el segundo es el beneficiario de los seguros de responsabilidad, es decir, la víctima". [Resaltado original]

En síntesis: luego de un camino no exento de tropiezos, caracterizado en un primer tramo por la negación del estatus de consumidor a todos aquellos no vinculados directamente con el proveedor, asistimos hoy a su reconocimiento pleno, derivado de una correcta interpretación de normas puntuales del Código que no hacen sino ampliar generosamente el conjunto de supuestos y personas tuteladas por el Estado peruano, con lo cual se hace realidad el propósito del artículo 65 de la Constitución de defender el interés de los consumidores. Esperemos que las posteriores conformaciones de la Sala mantengan el criterio imperante.

Una razón más es posible esgrimir en atención a la líneas finales del párrafo anterior, cual es la de sustentar la tutela de este tipo de consumidores periféricos o equiparados en el artículo 1 Constitucional que coloca la defensa de la persona y el respeto de su dignidad como el fin supremo de la sociedad y el Estado. Ante todo, debe procurarse una plena tutela de la persona en el mercado, en atención a su calidad de profano en un ámbito tan profesionalizado como el actualmente existente.

Por lo demás, la aplicación de las normas vinculadas a este tipo de consumidores ha sido hecha, correctamente, en casos que han concitado la atención de los medios periodísticos por tratarse de conductas discriminatorias hacia personas homosexuales. Entre otros, cabe citar la Resolución $\mathrm{N}^{\circ}$ 3255-2015/SPC-INDECOPI, del 19.10.2015, emitida en Julio César Lavalle Sotillo y otro c. Mall Service S.A.C. - Plaza San Miguel, que comento más adelante, en el cual se discutía la condición de consumidores de los denunciantes, habida cuenta que no adquirieron producto o servicio alguno de la empresa denunciada. La Sala decidió que, en atención al CPDC y a su actual cobertura tuitiva, los denunciantes igual merecían ser calificados como consumidores para efectos de la aplicación de dicha normativa. Decisión impecable, por cierto. 


\section{Revista Eletrônica da Faculdade de Direito da Universidade Federal de Pelotas (UFPel) Dossiê Consumo e Vulnerabilidade: a proteção jurídica dos consumidores no século XXI. Vol. 03, N. 1, Jan-Jun., 2017.}

ISSN - 2448-3303

\section{3) La problemática derivada del uso mixto del bien o servicio.}

Una de las problemáticas más recurrentes en la adquisición de productos y servicios es el doble destino que suele dárseles; es decir, tanto un uso personal o familiar, como su empleo comercial. El tema plantea la cuestión siguiente: definir si aquel que utiliza un bien o servicio de forma mixta puede ser considerado consumidor, o no, a la luz del CPDC. Según su artículo IV,1.3, "[e]n caso de duda sobre el destino final de determinado producto o servicio, se califica como consumidor a quien lo adquiere, usa o disfruta". Nótese que la norma alude a la "duda" existente para determinar dicha condición.

Los órganos resolutivos del INDECOPI han hecho denodados esfuerzos para resolver de la mejor manera tal situación. Así, han apelado, por ejemplo, al singular criterio de la proporcionalidad del uso, según el cual se es consumidor si el producto o servicio se utiliza más para fines personales que comerciales [Resol. $\mathrm{N}^{\circ}$ 315-2002/CPC-INDECOPI, del 2.5.2002] ${ }^{34}$ hasta el más reciente de analizar las características del producto o servicio adquirido; es decir, si sus características permiten determinar su uso mixto, se considerará consumidor al denunciante, salvo prueba en contrario, siendo importante el caudal probatorio aportado al procedimiento. Si se trata, de otro lado, de bienes o servicios cuyas características hacen deducir un uso empresarial no se aplicará la presunción anotada. Esto último fue lo que se expresó en la Resol. $\mathrm{N}^{\circ} 3591$ 2012/SPC-INDECOPI, de fecha 11.12.2012, en Herminio Edward Espinoza Povis c. Novoautos S.A. Lamentablemente, la Sala erró en la calificación de consumidor del denunciante.

En el caso, el señor Espinoza adquirió un auto marca JAC, modelo A-138 del año 2009. Luego de adquirido presentó fallas que no fueron solucionadas en su totalidad, pese a que lo internó en los talleres de la vendedora. En el procedimiento se determinó que se compró la unidad para dedicarla al servicio de taxi, dentro del programa denominado "Mi Taxi Asociación”. Luego, en su escrito de apelación contra lo resuelto por la Comisión de Protección al Consumidor Lima Sur $\mathrm{N}^{\circ} 2$, que declaró improcedente la denuncia porque dicho vehículo fue adquirido para el desempeño de su labor como taxista, expresó que era un "taxista profesional y especializado" y que se procuró el vehículo "para destinarlo al giro propio de su negocio". Todas estas pruebas eran suficientes para confirmar la decisión de la Comisión, pues era claro que el bien había sido adquirido para fines de su oficio, por lo que siendo parte de este no cabía decidir en otro sentido.

\footnotetext{
${ }^{34}$ Cit. ESPINOZA ESPINOZA, Juan. Derecho de los Consumidores, Editorial Rodhas, Lima, 2006, p. 19.
} 


\section{Revista Eletrônica da Faculdade de Direito da Universidade Federal de Pelotas (UFPel) Dossiê Consumo e Vulnerabilidade: a proteção jurídica dos consumidores no século XXI. Vol. 03, N. 1, Jan-Jun., 2017.}

ISSN - 2448-3303

Sin embargo, apelando al criterio anotado, la Sala se decantó por revocar tal pronunciamiento en virtud a que los atributos del bien configuraban un uso mixto y a que la parte denunciada no había desvirtuado las alegaciones del denunciante; aunque en el voto en discordia se aprecie aquello que incluso el periodismo jurídico ${ }^{35}$ le reclamó al Colegiado: un mayor celo en el análisis de las pruebas y la consecuente declaración de improcedencia de la denuncia, ante la ausencia del requisito de la "duda sobre el destino final" del bien establecido en el artículo IV, 1.3 del CPDC.

La autoridad ha encontrado el camino correcto, como dan cuenta numerosas resoluciones de la Sala. Prueba de esto es una reciente resolución emitida en el caso César Melgar Condori c. Servicentro Cecilia E.I.R.L., N 0913-2017/SPC-INDECOPI, del 27.2.2017. En el caso, el denunciante acudió al establecimiento de la denunciada a llenar el tanque de su vehículo, el cual una vez en circulación se apagó repentinamente, no volviendo a encender. Luego de su revisión se determinó que había rastros de combustible distinto al usado por el vehículo [petróleo]. El vehículo era de propiedad de su empresa [Melgar Condori E.I.R.L.], por lo que existía duda en cuanto al destino final del mismo: fin personal o empresarial. Con buen criterio, la Sala señaló que para determinar si el denunciante califica o no como consumidor, habrá que atender a las características del bien adquirido, pues si de ellas se desprende que puede ser aplicado a usos diversos [fines personales como empresariales], deberá considerarse como tal al accionante. Precisó, en este orden, que "[s]iendo así, en el caso de los bienes cuyas características permitan inferir que su uso es destinado normalmente a un ámbito personal y/o familiar, se considerará al denunciante como consumidor protegido, salvo prueba en contrario, para lo cual serán de gran importancia los medios probatorios que se aporten en el expediente. Es importante precisar que no se tomará en cuenta el carácter cuantitativo a fin de evaluar el uso mixto de un bien, de tal manera el denunciante no deberá demostrar en un determinado caso la proporción de uso personal o comercial que dio a un bien a fin de ser calificado como consumidor". En esa lógica, argumentó que "dado que la finalidad del sistema de protección al consumidor consiste en corregir la asimetría informativa entre consumidores y proveedores, en tanto no se acredite que un producto o servicio pasible de uso mixto ha sido destinado exclusivamente a una actividad empresarial o comercial, deberá considerarse que el usuario es un consumidor", para finalmente señalar que dicho criterio "[s]i bien (...) ha sido empleado para aquellos casos en que los denunciantes constituidos como personas naturales adquieren un bien y le brindan una actividad económica accesoria o eventual, tal análisis también sería aplicable a las personas naturales que usan o disfrutan un bien de manera personal y, a la vez, para las labores propias de su empresa o para la cual trabajan, pese a no ser las adquirentes del producto".

Con dicho criterio se resuelve satisfactoriamente el tema siempre polémico del uso mixto de bienes y servicios; pauta que solo debe aplicar cuando exista duda respecto al destino final de aquellos. Desde luego que los medios de prueba que se aporten al procedimiento serán determinantes para dilucidar tal cuestión.

\section{5) El derecho a la información}

En este apartado centraré mi atención en el numeral del CPDC según el cual "[1]os establecimientos que expenden comidas y bebidas y los servicios de hospedaje y hostelería están

\footnotetext{
${ }^{35}$ Ver nota en La Ley, año 6, número 60, Lima, enero 2013, p.9.
} 


\section{Revista Eletrônica da Faculdade de Direito da Universidade Federal de Pelotas (UFPel) Dossiê Consumo e Vulnerabilidade: a proteção jurídica dos consumidores no século XXI. Vol. 03, N. 1, Jan-Jun., 2017.}

ISSN - 2448-3303

obligados a colocar sus listas de precios en el exterior, de forma accesible y visible para consulta del consumidor" [art. 5, 5.3, 1ra. parte], que a partir de una decisión de la Sala Especializada en Protección al Consumidor fue vaciado de contenido.

En Defensa del Consumidor c. Inversiones Nacionales de Turismo S.A. se denunció al Hotel Libertador por no contar con una lista de precios en el exterior del local [la fachada, concretamente], como exigía la norma citada. A pesar que en la inspección realizada por la Secretaría Técnica de la Comisión de la Oficina Regional del INDECOPI - La Libertad se comprobó que su lista de precios se encontraba en su interior [en la recepción], igual fue sancionado con 2 UIT, ordenándose como medida correctiva su colocación en el lugar exigido por el Código. Al resolver la apelación interpuesta por la empresa hotelera sancionada, la Sala argumentó que dicho artículo "no puede interpretarse de forma aislada y bajo un criterio únicamente literalista, sino que resulta necesario efectuar una interpretación teleológica y sistemática del derecho a la información y las demás normas que buscan corregir la asimetría en la que se encuentran los consumidores en el mercado, a fin de establecer el verdadero sentido de tal disposición", añadiendo que no existirá vulneración de este derecho si pese a no colocar el listado de precios en el exterior del establecimiento, lo ubica en su interior, pues de este modo el consumidor podrá informarse debidamente de los costos involucrados en el servicio que pretende tomar [Resol. N²874-2013/SPC-INDECOPI, del 28.10.2013]. ${ }^{36}$

El Código persigue como fin último que el consumidor acceda a información veraz, suficiente, de fácil comprensión, apropiada, oportuna y fácilmente accesible, y en idioma castellano [art. 2, 2.3] para tomar una decisión de consumo adecuada; y todo esto se cumplía con la colocación de un listado de precios en la recepción del establecimiento hotelero, a la que podía acceder cualquier consumidor diligente; por lo que exigirle a la denunciada, como se deduce de lo resuelto por la Comisión, el cumplimiento de la exigencia normativa, parece un contrasentido. Por esta razón, es sensato el criterio de la Sala, porque además consulta la regulación sectorial, pero ¿cómo queda ahora la obligación legal contenida en esta norma del Código? Con la actual interpretación pues simplemente tal exigencia queda disuelta sin más; por tanto, restaurantes, bares, cafés, hostales y hoteles cumplirán con la obligación de informar al consumidor

\footnotetext{
${ }^{36}$ La Sala cita el D.S. N 029-2004-MINCETUR, Reglamento de Establecimiento de Hospedaje, en el cual se advierte la obligación de las empresas del rubro de mostrar en forma visible, tanto en la recepción como en las habitaciones, las tarifas del servicio.
} 


\section{Revista Eletrônica da Faculdade de Direito da Universidade Federal de Pelotas (UFPel) Dossiê Consumo e Vulnerabilidade: a proteção jurídica dos consumidores no século XXI. Vol. 03, N. 1, Jan-Jun., 2017.}

ISSN - 2448-3303

simplemente poniendo a su disposición -en el interior de los locales- los precios de sus productos o servicios.

El problema, bien visto, no es el criterio de la Sala sino la redacción de la norma. Si el artículo 1, 1.1 del Código exige en su apartado b), entre otros requisitos, que la información sea fácilmente accesible, y en el artículo 5, numerales 5.1 y 5.2 que la lista de precios de los productos sea fácilmente perceptible, de fácil acceso, agregándose que en ciertos casos pueden utilizarse terminales de cómputo, entonces ¿para qué apelar a una exigencia tan cerrada de publicitar estas listas en el exterior de los hoteles, y otros?

En síntesis: apreciamos cómo una interpretación literal de las normas -en este caso de una referente al derecho a la información- puede ocasionar resultados inconvenientes, y cómo el optar por un criterio amplio dar lugar a la pulverización de su contenido. Por ello, conviene una modificación del artículo 5, 5.3 del Código para evitar situaciones como las anotadas precedentemente.

\section{6) El deber de idoneidad y el momento de su vulneración}

Conjuntamente con el derecho a la información, el deber de idoneidad constituye uno de los soportes del sistema de protección al consumidor, el cual denota la correspondencia entre lo que un consumidor espera y lo que efectivamente recibe del proveedor, en función a lo que se hubiera ofrecido, la publicidad, información transmitida, las condiciones y circunstancias de la transacción, las características y naturaleza del producto o servicio, el precio, etc., atendiendo a las circunstancias del caso [art. 18, CPDC]. Tal es su importancia que en ocasiones algunas denuncias, como las relativas a discriminación, han sido resueltas no por aplicación de las normas del hecho denunciado, sino por las relativas a este deber. La cuestión relevante es definir el momento de su vulneración. Sobre el particular, se han formulado dos criterios interpretativos dispares.

En Juana Rufina Bocanegra Ayllón c. Importaciones Hiraoka S.A.C., la denunciante adquirió una refrigeradora que resultó defectuosa, siendo reemplazada por otra. Al poco tiempo, el producto sufrió fallas, que si bien fueron reparadas volvieron a aparecer, por lo que la compradora creyó que le habían vendido un producto usado. En ambas instancias del procedimiento sumarísimo se estableció que la idoneidad se viola desde el momento mismo en el que el producto 


\section{Revista Eletrônica da Faculdade de Direito da Universidade Federal de Pelotas (UFPel) Dossiê Consumo e Vulnerabilidade: a proteção jurídica dos consumidores no século XXI. Vol. 03, N. 1, Jan-Jun., 2017.}

ISSN - 2448-3303

o servicio sufre un desperfecto, siendo que las soluciones posteriores del proveedor son residuales a la falta de idoneidad. Así, se sancionó a Hiraoka con una multa de 0,5 UIT. Al resolver el recurso de revisión planteado por la empresa sancionada, la Sala situó la idoneidad no en cuanto al modo de ser del bien o de una cualidad suya [su funcionalidad], sino en orden al comportamiento del proveedor una vez que ha conocido el desperfecto de sus productos o servicios. Es decir, que la idoneidad se incumple cuando el proveedor limita, excluye o deniega los mecanismos de solución reconocidos u ofrecidos; como reemplazar el producto, repararlo o devolverle el dinero al consumidor, y no ante el desperfecto detectado [Resol. $\mathrm{N}^{\circ}$ 2221-2012/SC2-INDECOPI, del 19.7.2012].

A los pocos meses, esta interpretación quedó de lado. En Enrique Torrealva Reyes c. América Móvil Perú S.A.C [Resol. No 1008-2013/SPC-INDECOPI, del 25.4.2013] la Sala procedió a modificar el criterio imperante por otro según el cual el deber de idoneidad se viola no cuando el proveedor incumple alguna de las soluciones anotadas, que por cierto constituyen también derechos del consumidor, sino cuando el bien o servicio adolece de algún desperfecto. En otras palabras, poco importará que frente a una falla del producto o servicio el proveedor cumpla [o no] con repararlo, cambiarlo por otro o como último recurso devolver al consumidor el monto cancelado, pues tal deber ya habrá sido vulnerado siendo pasible de sanción administrativa. Las críticas a esta posición no se hicieron esperar.

Se acusó a la Sala de forzar a las empresas a la infalibilidad, la perfección; de generar incentivos para que el proveedor no se ocupe más de atender debidamente al consumidor ante cualquier reclamo, pues igual la sanción sería inevitable, y de afectar la economía del consumidor, debido al encarecimiento de los productos y servicios por causa del incremento en los costos para la mejoría de los procesos de control de calidad de las empresas. ${ }^{37}$

La idoneidad no se define en abstracto. El CPDC exige atender la naturaleza del producto o servicio y su aptitud para satisfacer la finalidad para la cual ha sido puesto en el mercado [art. 18, 2do. párr.], amén de las garantías a las que se encuentra obligado el proveedor, las cuales pueden establecerse legalmente, ser ofrecidas directamente o ser ínsitas al producto o servicio comercializado [art. 20].

Todo consumidor al adquirir un producto o servicio lo hace con la expectativa de satisfacer una necesidad puntual. Esta es la razón que guía su decisión de consumo. En atención a ello, el

\footnotetext{
${ }^{37}$ Ver SÚMAR, Oscar. "El deber de idoneidad y los ratones", blog Menú Legal, diario Gestión, tomado de la página http://blogs.gestion.pe/menulegal/2013/11/indecopi-el-deber-de-idoneidad.html, consultada el 28.11.2013.
} 


\title{
Revista Eletrônica da Faculdade de Direito da Universidade Federal de Pelotas (UFPel) Dossiê Consumo e Vulnerabilidade: a proteção jurídica dos consumidores no século XXI. Vol. 03, N. 1, Jan-Jun., 2017.
}

ISSN - 2448-3303

consumidor esperaría - en virtud a la información y garantías ofrecidas- que el producto o servicio no presente desperfectos o fallas durante cierto periodo de su vida útil; salvo los que aparecerán por efecto del uso continuo.

En atención a lo expuesto, el CPDC no enlaza la evaluación de la idoneidad con la conducta desplegada por el proveedor ante el acontecimiento de un defecto en el producto o servicio vendidos. Recordemos que los aspectos a ponderar en tal cometido aparecen definidos en el 2do. párrafo del artículo 18 y el artículo 20 referidos, por lo que no resulta correcto que el deber de idoneidad se piense todavía en relación a los remedios previstos en el artículo 97. Esto último era el inconveniente que planteaba el criterio anterior que, equivocadamente a nuestro juicio, incorporaba en la estimación de la idoneidad los mecanismos de solución a los que estaba obligado el proveedor frente a tal coyuntura. Y la mejor demostración de esto es que el artículo 19, sin más haga responsable directamente al proveedor "por la idoneidad y calidad de los productos y servicios ofrecidos [...]”. Así pues, creo acertada la interpretación de la Sala, que poniendo en juego los artículos del CPDC atrás referenciados, ha entendido que el deber de idoneidad debe "responder estrictamente al análisis respecto de si el producto adquirido o servicio prestado corresponde a lo esperado por el consumidor, sin perjuicio del comportamiento de los proveedores frente a los reclamos posteriores que pudieran plantearse por la existencia de fallas". De esta manera se distingue la situación misma del bien, cuya defectuosidad entrañará una vulneración del deber de idoneidad, y los remedios a los cuales podrán apelar los consumidores para protegerse debidamente de dicha vicisitud.

\begin{abstract}
El nuevo criterio no supone, vale aclarar, que la autoridad exija un preciso estándar de calidad. Lo único que persigue es el cumplimiento de la finalidad señalada en el artículo II del Título Preliminar del Código, cual es que los consumidores accedan a bienes y servicios idóneos; no descuidando, por supuesto, la conducta ulterior mostrada por el proveedor, la cual deberá considerarse al momento de graduar la sanción a imponer. La autoridad administrativa ha venido utilizando en diversas decisiones el criterio sentado en la Resolución $\mathrm{N}^{\circ}$ 1008-2013/SPC-INDECOPI, reseñada líneas arriba. Lo ha utilizado incluso hasta el momento en el que concluyo estas líneas, como puede apreciarse en la Resolución N ${ }^{\circ}$ 4917-2016/SPC-INDECOPI, del 20.12.2016, emitida en el caso Roberto Carlos Rivera Ramos c. Diveimport S.A. - Divecenter S.A.C.

De otro lado, es destacable que en muchas de ellas la Sala Especializada en Protección al Consumidor -sobre el deber de idoneidad- recurra en la argumentación al principio de vulnerabilidad del consumidor, ${ }^{38}$ recogido como política pública en el artículo VI. 4 del Título Preliminar del CPDC, según el cual “[e]l Estado reconoce la vulnerabilidad de los
\end{abstract}

\footnotetext{
${ }^{38}$ En la doctrina brasilera puede consultarse la obra del profesor HEINECK SCHMITT, Cristiano. Consumidores hipervulneráveis. A proteção do consumidor idoso no mercado de consumo, Editora Atlas, São Paulo, 2014, quien ha desarrollado líneas fundamentales sobre este tema, siempre tan actual.
} 


\section{Revista Eletrônica da Faculdade de Direito da Universidade Federal de Pelotas (UFPel) Dossiê Consumo e Vulnerabilidade: a proteção jurídica dos consumidores no século XXI. Vol. 03, N. 1, Jan-Jun., 2017.}

ISSN - 2448-3303

consumidores en el mercado y en las relaciones de consumo, orientando su labor de protección y defensa del consumidor con especial énfasis en quienes resulten más propensos a ser víctimas de prácticas contrarias a sus derechos por sus condiciones especiales, como es el caso de las gestantes, niñas, niños, adultos mayores y personas con discapacidad así como los consumidores de las zonas rurales o de extrema pobreza". Se trata, sin duda, de un principio que colorea el ámbito de protección del consumidor; que orienta ahora la actuación estatal y de sus órganos administrativos, judiciales y arbitrales; en pauta que ilumina la interpretación de la legislación sectorial; que marca el derrotero por el cual deberá guiarse la jurisprudencia emitida por la entidad estatal encargada de la resolución de los conflictos entre consumidores y proveedores, las decisiones de la justicia arbitral de consumo y las resoluciones judiciales; en el criterio orientador de los estudios doctrinarios, que no pueden obviar más la especial situación del consumidor en un mercado como el peruano tan dispar como informal y, en algunos casos, desprovisto de suficiente competencia; todo ello en armonía con lo dispuesto por el artículo I del CPDC, que instituye como principio rector de la política social y económica del Estado la protección de los derechos de los consumidores, dentro del marco del régimen económico previsto en la Constitución.

Así, ha señalado ${ }^{39}$ que teniendo en consideración que el consumidor se encuentra en una situación de vulnerabilidad técnica frente al proveedor, se considera que este es el responsable por la puesta a disposición en el mercado de productos que presenten defectos de funcionamiento, por cuanto su venta defrauda las expectativas que respecto a ellos tienen los consumidores; con lo cual el principio se convierte, como señalé, en pauta informadora de las decisiones de la autoridad. Habrá que esperar que el tiempo nos entregue mayores desarrollos jurisprudenciales sobre el mismo.

En otro orden, la Sala ha procedido a ampliar el deber de idoneidad que pesa sobre el proveedor, no circunscribiéndolo a un producto o servicio determinado. En efecto, ha interpretado que dicho deber debe abarcar incluso a todo aquello que rodea el proceso de su comercialización, como lo atinente a la seguridad y vigilancia del centro comercial, incluido el trato al consumidor, que no podrán afectar su tranquilidad y menos su dignidad como persona. Desarrollan este criterio las Resoluciones N $^{\circ} 3776-2014 / \mathrm{SPC}-$ INDECOPI, del 4.11.2014 [Ana Rosa Guerrero Cerna c. Hipermercados Tottus], 40352014/SPC-INDECOPI, del 25.11.2014 [Maricela Díaz Díaz c. Supermercados Peruanos S.A.], ${ }^{40}$ 0638-2017/SPC-INDECOPI, del 6.2.2017 [Verónica Paz Soldán Vera c. Supermercados Peruanos S.A.] y 0963-2017/SPC-INDECOPI, del 28.2.2017 [Leonardo Augusto Díaz Arriaga c. Hipermercados Tottus S.A.], entre otras.

Finalmente, cabe señalar que de acuerdo al artículo 108 del CPDC, modificado por el Decreto Legislativo $\mathrm{N}^{\circ} 1308$ [véase la nota a pie 2], pondrán fin al procedimiento la resolución de la autoridad administrativa que declara la improcedencia de la denuncia de parte "e) Si existe falta de legitimidad o interés para obrar". La Sala Especializada en Protección al Consumidor la ha definido como "la necesidad indisponible e insustituible de tutela jurisdiccional para la resolución de un conflicto de intereses intersubjetivo o una incertidumbre jurídica, ambas con relevancia jurídica. En otras palabras, "es la necesidad de acudir al órgano jurisdiccional, como único medio capaz de procesar y posteriormente declarar una decisión respecto del conflicto que están viviendo" [cursivas originales]. Así también, cuando "f) El proveedor subsana o corrige la conducta constitutiva de infracción administrativa con anterioridad a la notificación de la imputación de cargos". De acuerdo

\footnotetext{
${ }^{39}$ Por ejemplo, Resolución No 102-2015/SPC-INDECOPI, del 19.1.2015 [Kelly García Salazar c. Tiendas por departamentos Ripley S.A.]; Resolución N²519-2015/SPC-INDECOPI, del 17.8.2015 [Yuly Vilma Simón Barreto c. América Móvil Perú S.A.C.]; Resolución N 0124-2016/SPC-INDECOPI, del 13.1.2016 [Susana Fonseca Mejía c. Cencosud Retail Perú S.A.]; Resolución N 1411-2016/SPC-INDECOPI, del 25.4.2016 [José Ricardo Ríos Sánchez c. Supermercados Peruanos S.A.]; Resolución N²971-2016/SPC-INDECOPI, del 15.8.2016 [Mariela Elisa Granda Gamarra c. NBS Service S.A.]; Resolución N 3605-2016/SPC-INDECOPI, del 28.9.2016 [Gina Manuela Gando Gutiérrez c. General Motors Perú S.A.]; entre otras.

${ }^{40}$ Comento esta resolución en "Trato indigno a consumidores vulnerables”, en Actualidad Jurídica, número 258, Lima, pp. 167-168.
} 


\title{
Revista Eletrônica da Faculdade de Direito da Universidade Federal de Pelotas (UFPel) Dossiê Consumo e Vulnerabilidade: a proteção jurídica dos consumidores no século XXI. Vol. 03, N. 1, Jan-Jun., 2017.
}

ISSN - 2448-3303

\begin{abstract}
con la parte final del artículo 107 de dicho Decreto, el procedimiento en materia de protección al consumidor "se inicia con la notificación de la imputación de cargos al posible infractor". En este sentido, si el proveedor solucionara el problema que mantiene con el consumidor antes de la denuncia, o si lo hiciera hasta antes de la imputación de cargos, la misma deberá declararse improcedente; solución que resulta correcta, pues no tiene sentido activar el aparato estatal cuando lo que podría ser objeto de denuncia o ya lo es ha quedado finalmente solucionado, para satisfacción del consumidor. Sobre el particular, la Sala ya ha emitido sendos pronunciamientos, como los advertidos en las Resoluciones $\mathrm{N}^{\circ}$ 550-2017/SPC-INDECOPI, del 31.1.2017 [Norma Isabel Alcalá Paz c. Limaautos Automotriz del Perú S.A.C.], 0833-2017/SPC-INDECOPI, del 20.2.2017 [Gladys Agueda Arias de Molina y otro c. Automotriz Cisne S.R.L.- General Motors Perú S.A.], y 0928-2017/SPC-INDECOPI, del 27.2.2017 [Lourdes Paredes Carranza c. Innovación Turística S.A.C. - Catering del Norte S.A.C.], etc.
\end{abstract}

\section{6) Discriminación en el consumo}

Con base en el inciso 2do. del artículo 2 constitucional, la discriminación del consumidor se presenta como uno de los temas más delicados en sede del CPDC [art.38], y sensible en cuanto a su aplicación, como ha dicho un sector de la academia. ${ }^{41}$ Es también un tema difuso, pues muchos de los casos denunciados ante la autoridad no alcanzan a ser de esta índole, sea porque las pruebas alcanzadas no producen convicción sobre el hecho denunciado o porque simplemente se está ante un trato diferenciado; por lo que terminan resolviéndose bajo normativa distinta o declarándose infundados, según corresponda. De acuerdo con el diccionario de la RAE, discriminar significa "seleccionar excluyendo" y "dar trato de inferioridad a una persona o colectividad por motivos raciales, religiosos, políticos, etc."

\begin{abstract}
En una publicación reciente se ha mencionado, con acierto, que "[1]a discriminación se manifiesta también durante el consumo, en las relaciones que se forjan entre consumidores o usuarios y proveedores en un mercado: cuando una persona quiere acceder a un producto o un servicio ofrecido por un proveedor - empresa, empresario, negociante - y a cambio obtiene negativa, rechazo, obstaculización o maltrato por razones injustificadas y específicamente relacionadas a su raza, sexo, orientación sexual, origen, idioma, condición socioeconómica, credo y opinión política. Acá se detecta discriminación en el consumo, sin importar si el afectado es solo una persona o si pertenece a un grupo mayoritario o minoritario". 42

Los últimos años de aplicación del CPDC siguen mostrando que uno de los temas controvertidos a resolver por la autoridad administrativa es el de la discriminación, que a su vez revela una de las tantas taras que, lamentablemente, no ha podido desprenderse del común de ciudadanos de mi país. Vivimos, como acertadamente ha escrito un autor
\end{abstract}

\footnotetext{
${ }^{41}$ RODRÍGUEZ GARCÍA, Gustavo M. El consumidor en su isla. Una visión alternativa del sistema de protección al consumidor, Universidad del Pacífico, Lima, 2013, p.39.

${ }^{42}$ INDECOPI. Discriminación en el consumo y trato diferenciado ilícito en la jurisprudencia del Indecopi, Instituto Nacional de Defensa de la Competencia y de la Protección de la Propiedad Intelectual - Dirección de la Autoridad Nacional de Protección del Consumidor, Lima, 2015, p. 24.
} 


\title{
Revista Eletrônica da Faculdade de Direito da Universidade Federal de Pelotas (UFPel) Dossiê Consumo e Vulnerabilidade: a proteção jurídica dos consumidores no século XXI. Vol. 03, N. 1, Jan-Jun., 2017.
}

ISSN - 2448-3303

\begin{abstract}
nacional, un fenómeno de "normalización de la discriminación", esto es que "no parece ser una situación condenable o injusta, sino la simple reacción a diferencias naturales entre las personas". ${ }^{43}$ Es que a pesar de ser una nación democrática, no se ha aprendido aún que la convivencia social depende del respeto, solidaridad y tolerancia hacia los demás, con quienes se comparte un mismo presente, como un similar destino común. Y esto parece confirmarlo el Decreto Supremo $\mathrm{N}^{\circ}$ 006-2017-PCM, publicado en el diario oficial $E l$ Peruano el 27.1.2017, que aprueba la Política Nacional de Protección y Defensa del Consumidor, en el cual se pone de resalto que un importante número [de acuerdo con encuestas realizadas] de consumidores ha sido objeto de discriminación por los proveedores, o percibe que se los discrimina en la incursión que realizan en el mercado. Por cierto que este problema se acrecienta respecto de sectores poblaciones específicos, como resulta ser el concerniente al colectivo LGTB, que hacen denodados esfuerzos para lograr la tolerancia hacia sus comportamientos, particularmente afectivos, respecto del común de ciudadanos y proveedores, de manera especial.
\end{abstract}

Veamos los siguientes procedimientos:

[i] En un primer caso, Aldo Toledo Corazao c. Magali Elena Alarcón Yépez, la Sala precisó que cualquier afectado por discriminación deberá presentar sucedáneos de medios probatorios para corroborarla, pues no siempre se tienen pruebas directas que acrediten las alegaciones de los denunciantes. Así, revocó la decisión de la Comisión de la Oficina Regional del INDECOPI del Cusco, declarando infundada la denuncia [no haber permitido el ingreso del denunciante a una discoteca, debido a que personas de su apariencia y orientación sexual tenían un comportamiento inadecuado], porque la prueba presentada [un Acta de Constatación Policial en la cual no constaba el hecho denunciado, sino el mal comportamiento del afectado producto de su estado de embriaguez] no causó convicción al Colegiado [Resol. N ${ }^{\circ}$ 0688-2014/SPCINDECOPI, del 27.2.2014].

[ii] En otro, Juan Carlos Salinas Rojas c. América Express S.A., una denuncia por discriminación [el denunciante señaló que en el boleto de viaje que adquirió de la empresa aparecía la frase "Pasj malcriado", por lo que no utilizó el servicio contratado] fue resuelta aplicando las normas del deber de idoneidad. En primera instancia, la Comisión de Protección al Consumidor de Lima Sur $\mathrm{N}^{\circ} 2$ declaró fundada la denuncia por falta de idoneidad e infundada por discriminación, pues se comprobó en el procedimiento que la empresa no cometió discriminación contra el denunciante. No obstante, se entendió que un consumidor no esperaría encontrar en el documento de viaje calificativos negativos de ningún tipo que no guarden relación con el servicio contratado, y aun cuando la inclusión de ese tipo de frases sea producto de un error de los

\footnotetext{
${ }^{43}$ ARDITO VEGA, Wilfredo. "Responsabilidad social empresarial y discriminación”, en Derecho PUCP, Revista de la Facultad de Derecho de la Pontificia Universidad Católica del Perú, número 64, Lima, 2010, p. 245.
} 


\section{Revista Eletrônica da Faculdade de Direito da Universidade Federal de Pelotas (UFPel) Dossiê Consumo e Vulnerabilidade: a proteção jurídica dos consumidores no século XXI. Vol. 03, N. 1, Jan-Jun., 2017.}

ISSN - 2448-3303

dependientes del transportista [como alegó la denunciada], "las incidencias o los problemas internos de la empresa... no pueden ser opuestos al consumidor". De acuerdo con la Sala, la infracción se produjo al momento de la compra del boleto. [Resol. $N^{\circ}$ 0129-2014/SPCINDECOPI, del 20.1.2014].

[iii] Otras veces, la opción por la discriminación termina siendo cuestionable. En Indecopi c. Peruvian Airlines, se impidió que un grupo de pasajeros que padecían sordomudez abordaran el vuelo Lima-Iquitos [lograron hacerlo después], porque se encontraban acompañados de una sola persona que facilitaba la comunicación entre ellos y la aerolínea, pues siendo más de cinco los pasajeros se requería del concurso de un acompañante por cada uno, como medida de seguridad, y porque así se encontraba establecido en sus manuales de operaciones aprobados por la autoridad competente. Finalmente se confirmó la sanción de 45 UIT por discriminación, porque se "condicionaba el acceso de cinco personas sordomudas a un vuelo a que estuvieran acompañadas por una persona, por considerar que su discapacidad, en sí misma, constituía un riesgo potencial para el desencadenamiento de cualquier hecho que afectara su seguridad", teniendo como sustento legislación sectorial [Ley N² 28735 y Resol. Directoral N² 218-2003-MTC-12], según la cual solo se puede exigir un acompañante para personas con discapacidad cuando dichas personas no sean autosuficientes o lo recomiende un certificado médico [Resol. $\mathrm{N}^{\circ}$ 0854-2014/SPC-INDECOPI, del 13.3.2014]. La cuestión problemática era que los manuales que permitían a la empresa actuar en ese sentido habían merecido la aprobación de la autoridad del sector, por lo que el INDECOPI se colocaba por encima de sus decisiones para el tráfico aéreo. Por ello, era más sensato, dada la complejidad del tema, optar por la nulidad de la decisión de primera instancia, para que se solicitara la opinión de la Dirección General de Aeronáutica Civil como ente responsable de la aprobación de los manuales operacionales de la aerolínea, como sugirió el voto en discordia. Con mayores elementos de juicio, quizá el recurso a la discriminación habría quedado de lado.

[iv] Por último, uno de los casos más publicitados por los medios de comunicación [la discriminación produce esto], fue el de Miguel Ángel Céliz Ocampo c. Rímac Internacional Compañía de Seguros y Reaseguros [Resol. № 2135-2012/SC2-INDECOPI, del 11.7.2012], en el cual la decisión final de la Sala tuvo que recurrir a un voto dirimente dada la diversidad de posiciones entre sus miembros. La denuncia versaba sobre la negativa de la empresa de seguros de afiliar a la hija del denunciante que padecía síndrome de down al seguro de asistencia médica 


\title{
Revista Eletrônica da Faculdade de Direito da Universidade Federal de Pelotas (UFPel) Dossiê Consumo e Vulnerabilidade: a proteção jurídica dos consumidores no século XXI. Vol. 03, N. 1, Jan-Jun., 2017.
}

ISSN - 2448-3303

"Red Salud". La denunciada adujo que por política de sus productos prefería los de baja siniestralidad, por lo que personas con este tipo de enfermedad no eran asegurables.

En primera instancia, se sancionó a la empresa por discriminación, imponiéndole una multa de 50 UIT y una medida correctiva consistente en afiliar a la afectada al seguro solicitado. En vía de apelación, la Sala sentó tres posturas: por un lado, se sostuvo que en los hechos se apreciaba el tipo básico de infracción consistente en la selección injustificada de clientela [art. 38.2 CPDC], porque de acuerdo a los actuados se demostraba que en anteriores oportunidades la empresa había afiliado a sus seguros a personas con el mismo mal. Del mismo modo, se planteó el trato diferenciado lícito, debido a la inexistencia de norma que obligue a las aseguradoras a afiliar a personas con este padecimiento y a la libertad de contratación de las empresas del rubro; por último, el criterio que prevaleció -y al cual nos afiliamos sin reservas- fue considerar el hecho como un típico acto discriminante, porque en oportunidades anteriores se había procedido al aseguramiento de estas personas y porque no existía impedimento alguno para proceder en este sentido respecto de la hija del denunciante, ya que pudieron aplicarse restricciones o incremento en la prima en atención a su padecimiento.

\begin{abstract}
Sin lugar a equivocación, los casos más sensibles en materia de discriminación en el consumo suelen ser aquellos referidos a parejas homosexuales, especialmente en lo que concierne a la manifestación libre de sus afectos. Quiero referir, especialmente, dos casos puntuales que concitaron la atención de la prensa nacional, que tuvieron lugar en un centro comercial y en una discoteca.

En Julio César Lavalle Sotillo y otro c. Mall Service S.A.C./ Plaza San Miguel [Resol. N 3255-2015/SPC-INDECOPI, del 19.10.2015], una pareja homosexual acudió a un centro comercial, luego de almorzar en un restaurante cercano a él, para descansar. Situados en su zona central, y como cualquier pareja, empezaron a acariciarse. Minutos después fueron abordados por el vigilante quien les increpó que en ese lugar no podían hacer tales cosas, ya que no era un parque sino un centro comercial, y que debían retirarse. Luego de responderle que no hacían nada malo y que su conducta era igual a la de otras personas, el agente contestó que "[s]on dama y caballero, es otra cosa", y dirigiéndose a uno de los jóvenes dijo: "Si estarías en un parque, con gusto, eres libre", luego de lo cual los amenazó con llamar a la policía. En la resolución del colegiado se determinó la comisión de la conducta infractora que, a su vez, vulneró la dignidad de los denunciantes, su tranquilidad y trato igualitario, dada su condición homosexual; aunque reduciendo el monto de la sanción, de 10 a 8 UIT, por existir una circunstancia atenuante consistente en las disculpas ofrecidas por el centro comercial.

Como expresé en su oportunidad, ${ }^{44}$ las parejas homosexuales tienen derecho a manifestarse con libertad, a expresar sus afectos conforme a sus sentimientos más íntimos, ${ }^{45}$ a ser respetadas, y a gozar de todas las oportunidades que el mercado brinda
\end{abstract}

\footnotetext{
${ }^{44}$ CARRANZA ÁLVAREZ, César. “¡Si estás en un parque, eres libre! Discriminación en centros comerciales por razón de la orientación sexual de los consumidores”, en Diálogo con la Jurisprudencia, número 207, agosto de 2015 , p. 223.

${ }^{45}$ Con la exigencia, aplicable también a las parejas heterosexuales, de no realizar actos de tipo obsceno que afecten la convivencia social. Como se indica en el considerando 65 de la resolución "[...], esta Sala considera pertinente
} 


\section{Revista Eletrônica da Faculdade de Direito da Universidade Federal de Pelotas (UFPel) Dossiê Consumo e Vulnerabilidade: a proteção jurídica dos consumidores no século XXI. Vol. 03, N. 1, Jan-Jun., 2017.}

ISSN - 2448-3303

para acceder y disfrutar de productos y servicios diversos. Así, abordar a dos muchachos en el interior de un centro comercial por un dependiente de la empresa, pedirles que se retiren por sus muestras de afecto bajo amenaza de llamar a la policía, sugerirles que su "libertad" de actuar queda reducida a los parques, y que lo reprochable de su comportamiento se debía a su homosexualidad a pesar de tratarse de un hecho realizado a esa misma hora por otras personas, constituye sin más una práctica aberrante que debe condenarse en todos sus términos.

Punto aparte merece la reducción de la sanción a la empresa denunciada, pues hubiese sido deseable que se emitieran señales claras al mercado de la prohibición de este tipo de conductas. ¿Una multa de esa magnitud, puede desincentivar comportamientos discriminatorios futuros?

En el procedimiento de oficio seguido contra la empresa Discorp Perú S.A.C., propietaria de la discoteca Ama ubicada en la ciudad de Trujillo [Resol. N ${ }^{\circ}$ 2116-2016/SPCINDECOPI, de fecha 8.6.2016], aquella fue procesada administrativamente por haber retirado de sus instalaciones a una pareja homosexual por mostrar supuestamente un comportamiento "excesivo" en la pista de baile, consistente en abrazos y algunos tocamientos que incomodaron a los restantes clientes.

En primera instancia, la Comisión de la Oficina Regional del Indecopi - La Libertad encontró responsable a la empresa, al haberse comprobado que incurrió en un trato discriminatorio contra la pareja al expulsarlos del interior del local, pese a que otras parejas realizaban similares comportamientos, imponiéndole una multa de 50 UIT y disponiéndose su inscripción en el Registro de Infracciones y Sanciones del Indecopi, más dos medidas correctivas consistentes en publicar -en redes sociales, página web y en la entrada de la discoteca - un aviso que indicara que la empresa no realizaba ningún tipo de actos discriminatorios, así como capacitar a su personal directo e indirecto para que evitaran prácticas de este tipo.

La Sala Especializada en Protección al Consumidor al resolver la apelación formulada por la empresa sancionada, resolvió por mayoría declarar infundada la acción de oficio, pues consideró que efectivamente los jóvenes homosexuales sí habían realizado un comportamiento excesivo que perturbó a los demás asistentes, como se desprendían de los vídeos entregados por la empresa procesada así como de las declaraciones juradas del personal y clientes que entregó, también, aquélla.

Lo discutible en este caso es la valoración que se hizo de los medios probatorios aportados al procedimiento administrativo, de cara a la confirmación o no del tipo infractor. Así, tratándose de los vídeos que registraron el incidente, tanto la Comisión como el vocal firmante del voto en discordia coincidieron en afirmar que estos no mostraban una conducta excesiva de la pareja, sino por el contrario, comprobaban el trato discriminatorio realizado contra ellos. La Sala, por su parte, observó todo lo contrario. De otro lado, es llamativo que se hayan valorado declaraciones juradas que provenían del personal de la empresa en cuestión y de algunos clientes, pues no cabía duda que ellas no tenían otro propósito que liberarla de responsabilidad. ¿Podía esperarse cosa distinta de los empleados respecto a su centro laboral? ¿Podían resultar creíbles unas afirmaciones que provenían de clientes, respecto de los cuales no se sabía si habían estado presentes o no el día del incidente?

Por último, cabe un último cuestionamiento: la multa impuesta en primera instancia por la Comisión a la procesada, cuyo monto ascendió a 50 UIT. Estimo que no puede aceptarse que ante un evento que daña la propia dignidad del ser humano se impongan sanciones de esa magnitud, que de acuerdo al CPDC representa el tope máximo de sanción para infracciones leves. Si se aspira a que la colectividad confíe en la autoridad; si realmente existe un propósito de cuidado del consumidor en el mercado, en el cual resulta ser un profano como sujeto vulnerable; si queremos contribuir a su confianza en ese espacio donde satisface a diario sus necesidades más urgentes; si se desea, en fin, un mercado

manifestar su rechazo a las conductas de índole obscena realizadas en un lugar público por cualquier persona, independientemente de su orientación sexual, ya que tanto las personas heterosexuales como las personas homosexuales deben contribuir con mantener una convivencia social armónica y con el orden público". 


\section{Revista Eletrônica da Faculdade de Direito da Universidade Federal de Pelotas (UFPel) Dossiê Consumo e Vulnerabilidade: a proteção jurídica dos consumidores no século XXI. Vol. 03, N. 1, Jan-Jun., 2017.}

ISSN - 2448-3303

donde reine el respeto, la tolerancia y la solidaridad de los proveedores hacia los consumidores, entonces parece imperiosa la necesidad de actuar con severidad. Más aún, cuando se trate de consumidores tan vulnerables como las parejas del mismo sexo.

La línea divisoria entre un hecho discriminatorio del que no lo es resulta ser muy tenue, por lo que siempre existirá el riesgo de sancionar al proveedor por una conducta que podría estar más cercana a una práctica comercial común, justificada y no sancionable [p.e., impedir el ingreso a una discoteca a quien no cuenta con la tarjeta de socio, o establecer cierto trato preferente para clientes bancarios de cuentas premium o millonarias, o atender en primer orden a viajeros vip en líneas aéreas para vuelos nacionales o internacionales, etc.], o al tipo simple de infracción aludido líneas atrás.

Por tanto, la autoridad deberá ser sumamente cuidadosa al momento de analizar y resolver denuncias de esta clase, incluso si algunas de ellas resultan ser sensibles para la prensa y el público en general, por lo que una rigurosa valoración de las pruebas aportadas al procedimiento es necesaria para lograr este cometido.

La discriminación, como señalé, suele ser un tema difuso, ya que puede considerarse como tal a un número muy vasto de conductas; que en no pocos casos podría, incluso, tener su fuente en la "sensibilidad" de la propia persona que "percibe" un trato discriminante por parte del proveedor. ${ }^{46}$ Así, una mirada penetrante, un gesto adusto o contrariado, el tono de voz alto, una indicación imperativa, una orden, una llamada de atención, e incluso hasta el silencio, pueden ser considerados por quien los recibe como un trato discriminatorio, susceptible de poner en movimiento el aparato administrativo estatal.

No es un secreto, aunque muchos se empeñen en negarlo, que la educación que se imparte desde la temprana edad, y que continúa en la escuela primaria y secundaria, está generando un tipo de ser humano hipersensible; capaz de sentirse afectado, herido o socavado en sus firmes creencias o su propia personalidad con tanta facilidad que hasta un viento fuerte podría quebrarlo. Son, a no dudar, la "cristalería fina" que ya camina por el planeta, y que con acierto el escritor español Javier MARÍAS ha caracterizado como "la tiranía de los pusilánimes". 47 En una época de creciente infantilización de la persona, esta podría considerar discriminante cualquier comportamiento del proveedor que, para otros, no serían más que normales o propios del comercio. De ahí la atención que reclamo de la autoridad.

\footnotetext{
${ }^{46}$ Entre otros, tenemos el caso de una persona que adquirió una computadora que al momento de su instalación presentó problemas en el disco duro, y que atribuyó a la empresa denunciada un trato discriminatorio ipor no haber asistido a una audiencia de conciliación! Susana Fonseca Mejía c. Cencosud Retail Perú S.A., Resolución N ${ }^{\circ}$ 0124-2016/SPCINDECOPI, del 13.1.2016.

${ }^{47}$ MARÍAS, Javier. “La tiranía de los pusilánimes”, El País, edición del 28.6.2015, Madrid (versión digital).
} 


\section{Revista Eletrônica da Faculdade de Direito da Universidade Federal de Pelotas (UFPel) Dossiê Consumo e Vulnerabilidade: a proteção jurídica dos consumidores no século XXI. Vol. 03, N. 1, Jan-Jun., 2017.}

ISSN - 2448-3303

\section{7) Palabras finales}

A pocos años de la vigencia del CPDC el trabajo realizado por la Sala Especializada en Protección al Consumidor del INDECOPI ha sido importante, pues ha contribuido conjuntamente con los aportes de la doctrina- a la interpretación y esclarecimiento de sus disposiciones; aunque ello haya significado la modificación de algunos de sus pronunciamientos anteriores. Pero ese esfuerzo ha generado también criterios cuestionables que han ido más allá del texto del Código o vaciado de contenido a alguna de sus normas, como se comprobó.

En todo caso, este es el panorama encontrado en la aplicación de una norma que -al lado de la Constitución y el Código Civil, en importancia- destaca por su objetivo de tutelar a la persona en el mercado y equilibrar las relaciones que entabla con el proveedor de los bienes y servicios que requiere para su vida diaria, respecto del cual se encuentra en un estado de inferioridad y, por ende, de vulnerabilidad.

\section{8) Referencias}

ARDITO VEGA, Wilfredo. "Responsabilidad social empresarial y discriminación”, en Derecho PUCP, Revista de la Facultad de Derecho de la Pontificia Universidad Católica del Perú, número 64, Lima, 2010, pp. $245-262$.

CARRANZA ÁLVAREZ, César. “Son consumidores los garantes de deudas ajenas? Notas a una reciente resolución del Indecopi”. En: Revista Jurídica del Perú, número 138, agosto 2012, Lima, pp. 299-318.

"¡Cambio de rumbo! Los garantes de deudas ajenas y su condición de consumidores”. En: Actualidad Jurídica, tomo 227, octubre 2012, Lima, p. 268.

"De nuevo sobre las notificaciones de cobro remitidas a terceros". En: Diálogo con la Jurisprudencia, número 193, octubre 2014, Lima, pp. 293-297.

"El nuevo perfil del consumidor en la legislación peruana". En: Revista de Derecho de la Competencia, Facultad de Ciencias Jurídicas de la Pontificia Universidad Javeriana, volumen 5, número 5, enerodiciembre 2009, Bogotá, pp. 107-132.

Lima, pp. 167-168.

"Trato indigno a consumidores vulnerables", en Actualidad Jurídica, número 258,

“Si estás en un parque, eres libre! Discriminación en centros comerciales por razón de la orientación sexual de los consumidores”. En: Diálogo con la Jurisprudencia, número 207, agosto de 2015, pp. 219-224.

ESPINOZA ESPINOZA, Juan. Derecho de los Consumidores, Editorial Rodhas, Lima, 2006.

"Primeras reflexiones a propósito del Código de Protección y Defensa del Consumidor”. En: Actualidad Jurídica, tomo 202, setiembre 2010, Lima, pp. 15-18.

"La tutela del consumidor en el Perú: una protección en dos escenarios". En: Actualidad Jurídica, tomo 239, octubre 2013, Lima, pp. 279-283.

GUTIÉRREZ CAMACHO, Walter. En: Reflexiones a propósito del Código de Protección y Defensa del Consumidor, Quincuagésima reunión INTERCAMPUS, María Matilde Schwalb (editora), Universidad del Pacífico, Lima, 2010.

HEINECK SCHMITT, Cristiano. Consumidores hipervulneráveis. A proteção do consumidor idoso no mercado de consumo, Editora Atlas, São Paulo, 2014. 


\section{Revista Eletrônica da Faculdade de Direito da Universidade Federal de Pelotas (UFPel) Dossiê Consumo e Vulnerabilidade: a proteção jurídica dos consumidores no século XXI. Vol. 03, N. 1, Jan-Jun., 2017.}

ISSN - 2448-3303

INDECOPI. Discriminación en el consumo y trato diferenciado ilícito en la jurisprudencia del Indecopi, Instituto Nacional de Defensa de la Competencia y de la Protección de la Propiedad Intelectual - Dirección de la Autoridad Nacional de Protección del Consumidor, Lima, 2015.

LIMA MARQUES, Claudia. "Campo de Aplicação do CDC”. En: BENJAMIN, Antonio Herman V., Claudia LIMA MARQUES y Leonardo ROSCOE BESSA, Manual de Direito do Consumidor, Revista dos Tribunais, $6^{\text {ta. }}$ edição [revista, atualizada e ampliada], São Paulo, 2014.

MARÍAS, Javier. "La tiranía de los pusilánimes", El País, edición del 28.6.2015, Madrid, tomado de la página <http://elpais.com/elpais/2015/06/24/eps/1435156852_290193.html>, consultada el 15.3.2017.

RODRÍGUEZ GARCÍA, Gustavo M. El consumidor en su isla. Una visión alternativa del sistema de protección al consumidor, Universidad del Pacífico, Lima, 2013.

ROJAS KLAUER, Carlos. "La microempresa y su consolidación como consumidor final. Gregorio E.I.R.L.”. En: Diálogo con la Jurisprudencia, número 158, noviembre 2011, Lima, pp.65-68.

RUBIO CORREA, Marcial. Estudio de la Constitución Política de 1993, Fondo editorial de la Pontificia Universidad Católica del Perú, tomo III, Lima, 1999.

SÁENZ DÁVALOS, Luis. "La defensa del consumidor en el Derecho Constitucional”. En: Revista Jurídica del Perú, número 42, Trujillo, 2003, pp. 115-132.

SÚMAR, Oscar. "El deber de idoneidad y los ratones", blog Menú Legal, diario Gestión, tomado de la página <http://blogs.gestion.pe/menulegal/2013/11/indecopi-el-deber-de-idoneidad.html >, consultada el 28.11.2013.

2011.

(Ed.). Ensayos sobre protección al consumidor en el Perú, Universidad del Pacífico, Lima, 